Acute and Chronic Sulfur Dioxide Fumigation of Piñon Pine Seeds and Seedlings:

Data Compilation

Michael L. Trujillo

Roger W. Ferenbaugh

Ernest S. Gladney

Richard G. Bowker*

"Collaburator, Department of Biology, Alma College, Alma, MI 48801.

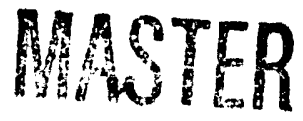




\title{
ACUTE AND CHRONIC SULFUR DIOXIDE FUMIGATION OF PIÑON PINE SEEDS AND SEEDLINGS: DATA COMPILATION
}

\author{
by \\ Michael L. Trujillo, Roger W. Ferenbaugh, Ernest S. Gladney, and Richard G. Bowker
}

\begin{abstract}
Piñon pine germinating seeds, emergent seedlings, and oneyear-old seedlings were exposed to sulfur dioxide under both acute and chronic exposure conditions. These fumigations were conducted in order to determine the potential for damage to piñon pine in southwestern national parks and monuments where there is potential for exposure to elevated sulfur dioxide concentrations from smelters and power plants. Injury was apparent only in acute fumigations of one-yearr-old seedlings at ambient sulfur dioxide concentrations of greater than $3 \mathrm{ppm}$. Chronic fumigations were conducted only at ambient concentrations of $0.2 \mathrm{ppm}$. Piñon pine resistance was evidenced by lack of effect of fumigation on biomass and growth parameters. Growth rate data for both experimental and control seedlings were fit to a linear growth model with a correlation $\left(\mathrm{r}^{2}=0.95\right)$.

The results of this study agree with other data in the literature and indicate that damage from elevated sulfur dioxide concentrations in southwestern national parks and monuments is much more likely for other, more sensitive, species than for piñon pine.
\end{abstract}

\section{INTRODUCTION}

The National Park Service (NPS) is concerned about potential sulfur dioxide impacts on national parks and monuments in the Southwest resulting from emissions from various sources, primarily power plants and smelters. The Los Alamos National Laboratory (LANL) entered into an Interagency Agreement with the NPS to use an experimental fumigation facility in existence at LANL to investigate the effects of controlled exposures of selected plant species to sulfur dioxide. Piñon pine (Pinus edulis) was selected because it is a major ecological component of southwestern parks and monuments. Two previous studies (Caldwell et al., 1976; Hill et al., 1974) have addressed the effects of sulfur dioxide on piñon pine and both found piñon pine to be resistant; however only acute fumigations were conducted.

Previous investigations on effects of sulfur dioxide on desert ecosystems include fumigation of range grasses (Davis et al., 1966), Indian ricegrass (Ferenbaugh, 1978), desert grasses (Johnson, 1974), and Mojave Desert plants (Thompson et al., 1980; Thompson et al., 1984) and uptake by desert soils (Ferenbaugh et al., 1979). In other related studies conducted at Los Alamos National Laboratory, Gladney et al. (1993a, b, c, d, e) collected piñon pine foliage and soil samples in the vicinity of piñon pine from five national parks and monuments surrounding the Four Corners area and analyzed them for sulfur content to provide baseline data.

The purpose of this study was to expose germinating seeds, emergent seedlings (germinants), and one-year-old piñon pine seedlings to sulfur dioxide under both acute and 
chronic exposure conditions to investigate effects of sulfur dioxide on growth parameters and to assess the various growth stages for damage.

\section{MATERIALS AND METHODS}

Fumigation Chambers - The LANL fumigation chambers used in these experiments are a modification of the continuous stirred tank reactor type chamber described by Heck et al. (1978). The chamber design is cylindrical ( $4 \mathrm{ft}$ in diameter by $4 \mathrm{ft}$ high) with a variablespeed impeller to enhance mixing and distribution of contents. Inlet air is filtered through activated charcoal beds, and test gases are introduced in dilute form at the inlet duct. The chambers are exhausted by a negative pressure, single-pass airflow system. The environmental control system consists of an atomizer to control humidity, a conditioning plenum for temperature control, airflow controllers, and micrometering valves to control fumigant concentration. Light is provided by metal halide lamps that provide approximately $3500 \mathrm{ftc}$ of light at $15 \mathrm{in}$. below the chamber ceiling. Photoperiod is regulated by a time clock. All parameters are continuously monitored by sensors located within the chambers.

Experimental Plant Material - Piñon pine seeds and one-year-old seedlings were purchased from Colo-Hydro Inc., Longmont, Colorado.

Eumigation of Germinating Seeds - Piñon pine seeds were sown in $14 \times 9 \times 2$ in. plastic trays on a 6:3:1 mixture of peat moss, vermiculite, and perlite. The trays were filled to a depth of 1.5 in., sixty seeds were spaced evenly in each tray, and the seeds covered with 0.125 in. of perlite. The trays were watered to saturation before being placed in the chambers, and then were watered lightly every other day throughout the study.

Chamber conditions were $\sim 25^{\circ} \mathrm{C}$, humidity 20 to $30 \%$, and lighted by fluorescent light. The experimental seeds were fumigated with $0.2 \mathrm{ppm}$ of sulfur dioxide for $7 \mathrm{~h}$ per day, 5 days per week. The airflow through the chambers was $8 \mathrm{scfm}$ (standard cubic feet per minute), resulting in 9.5 air changes per hour in the chambers. Trays were rotated daily in the chambers to ensure uniform exposure conditions.

A total of 1920 seeds was used in the study: 960 as experimental subjects and $\nsucc 60$ as controls. The 960 seeds in each set were divided into 16 trays of 60 seeds each. Two replicate fumigation experiments were conducted, using half of the experimental and control seeds in each experiment. Each experiment terminated five weeks after seeding. At the end of the five week period, the number of germinated seeds was counted, hypocotyl lengths were measured, and total dry weights were determined.

Chronic Exposure of Emergent Seedlings - Piñon pine seeds were sown in 1.5 in. diameter by 8 in. high plastic cylinders in a 6:3:1 mixture of peat moss, vermiculite, and perlite. Two seeds were planted ner cylinder. The cylinders were watered, covered with plastic sheeting, and maintained in a greenhouse until seed germination occurred. After germination, seedlings were thinned to one per container. Seedlings were watered twice per week and fertilized once per week with Burpee ${ }^{\circledR}$ 20-3-8 Evergreen mixture.

The chambers received $12 \mathrm{~h}$ light and $12 \mathrm{~h}$ dark per day (LD 12:12). Light intensity at floor level was $2000 \mathrm{ftc}$. Daytime temperature was controlled at $30^{\circ} \mathrm{C}$ and nighttime temperature at $20-25^{\circ} \mathrm{C}$. The chambers were maintained at ambient humidity of $20-30 \%$. Experimental seedlings were fumigated with $0.2 \mathrm{ppm}$ of sulfur dioxide for $7 \mathrm{~h}$ per day, 5 days per week. The airflow through the chambers was $8 \mathrm{scfm}$, or 9.5 air changes per hour.

The duration of this study was 16 weeks. Initially there were 80 seedlings each in the control and fumigated chambers. Twenty seedlings were removed from each chamber at 4 - 
week intervals, so that fumigated and control plants were obtained at 4 weeks, 8 weeks, 12 weeks, and 16 weeks. Whenever experimental seedlings were removed, they were replaced with other seedlings of similar size so that the canopy coverage characteristics within the chambers remained the same. The height of each seedling was measured prior to initiation of the study. Parameters that were measured at each harvest were post-treatment plant height, number of branches, and dry weight of needles, stems, and roots.

Acute Exposure of One-Year Seedlings - One-year-old seedlings were planted in a 6:3:1 mixture of peat moss, vermiculite, and perlite in small plastic buckets, $7 \mathrm{in}$. in diameter and 10 in. high. Three seedlings were planted per bucket, and the potting mixture level was brought up to the rim of the buckets to prevent damping off by elimination of the dead air space between the soil surface and the bucket rim. Seedlings were acclimatized in a greenhouse for two months after potting to overcome transplant shock before fumigation experiments were initiated. The seedlings were watered twice per week and fertilized once per week with Burpee ${ }^{\circledR}$ 20-3-8 Evergreen mixture.

Ambient chamber conditions during acute fumigations were temperature about $20^{\circ} \mathrm{C}$ and humidity $20-30 \%$. Light intensity at seedling level was about $2000 \mathrm{ftc}$. Airflow through the chambers was $10 \mathrm{scfm}$, or 11.9 air changes per hour, and acute exposures lasted for three hours. Sulfur dioxide was provided as a square wave function during the 3-h fumigation. Exposure concentrations ranged from 2.75 to $4.75 \mathrm{ppm}$ in $0.5 \mathrm{ppm}$ increments.

Seedlings were fumigated in sets of 6 per treatment. Each treatment was replicated 10 times. Four treatments were run each day, two in the morning and two in the afternoon. Scheduling of chambers (Table 1) according to treatment, day, and time of day was random. Controls are represented by zeros in Table 1. Plants were evaluated for visible injury two-to-five days after fumigation, whenever symptom expression was most obvious. Percent of total leaf area affected was estimated for each seedling.

Following evaluation of visual injury, seedling foliage was analyzed for sulfur content. For sulfur analysis, the 60 seedlings fumigated at each sulfur dioxide concentration were divided into two sets: those fumigated during morning exposures and those fumigated during afternoon exposures. Foliage from each set was composited into two samples, representing "old" and "new" needles. "New" needles were comprised of needles from first-year branches, and "old" needles were comprised of primary needles on the stem. This distinction was made because essentially all observed injury occurred on first-year branches, and the branch foliage was accordingly analyzed separately to determine if any correlation existed between injury and sulfur content. As a result of the AM-PM separation and the subsequent old-new separation, four samples for sulfur analysis were obtained at each fumigation level: AM-old, AM-new, PM-old, and PM-new. These samples were prepared and analyzed as described in the Sulfur Analysis section.

Chronic Exposure of One-Year Seedlings - One-year-old seedlings were received from the vendor in plastic cylindrical containers, 1.5 in. in diameter by 8 in. high. The seedlings used in this study were not transplanted from the cylindrical containers, but were acclimatized in the greenhouse for two months prior to fumigation. They were watered twice weekly and fertilized once per week with Burpee ${ }^{\circledR}$ 20-3-8 Evergreen mixture.

Chamber conditions for year-old seedlings were the same as previously described for emergent seedlings. Photoperiod was LD 12:12, with a light intensity of $2000 \mathrm{ftc}$ at seedling level. Daytime temperature was $25-30^{\circ} \mathrm{C}$, and nighttime temperature was $20-25^{\circ} \mathrm{C}$. Ambient humidity was $20-30 \%$. Seedlings were fumigated $7 \mathrm{~h}$ per day, 5 days per week, at a sulfur dioxide concentration of $0.2 \mathrm{ppm}$. Airflow was $8 \mathrm{scfm}$, or 9.5 air changes per hour. 
The experimental protocol for this 16 -week study was the same as previously described for emergent seedlings. Eighty seedlings initially were placed in each chamber. Twenty seedlings each were removed from the control and fumigated chambers at 4, 8, 12, and 16 weeks. Seedlings were replaced to maintain canopy coverage. Height and number of branches were determined for each seedling prior to fumigation. Parameters measured at each harvest were post-treatment height and number of branches, and dry weight of needles, stems and roots.

Sulfur analyses were performed on foliage from fumigated seedlings. Ten control and ten fumigated seedlings were selected for analysis at the end of each four week period and were prepared and analyzed as described in the Sulfur Analysis section.

Sulfur Analysis - Sulfur content of the piñon pine foliage was measured using a Leco Model SC-132 sulfur analyzer (Bower et al., 1986; Gladney et al., 1985). Vegetation samples were dried in a forced-air circulation oven at $60^{\circ} \mathrm{C}$ for 48 hours, ground through a $0.5 \mathrm{~mm}$ sieve in a Brinckmann Spex grinder, pelletized, and combusted in the Leco analyzer furnace. Water vapor was removed from the combustion gases by adsorption on magnesium perchlorate, and sulfur dioxide was then measured by infrared absorption. Measurements were standardized against National Bureau of Standards (NBS) Standard Reference Materials (SRM) 1572 citrus leaves (certified sulfur concentration of $4070 \pm 50$ $\mu \mathrm{g} / \mathrm{g}$ ). Each day's work was quality-assured by concurrent analysis of a variety of NBS SRMs and Alpha Resources biological materials. Quality assurance practices and procedures are detailed in Gautier et al., 1989.

Statistical Analysis of Data - One unforeseen problem arose as a result of the choice of seedlings for this project. Seedlings were randomly chosen in groups of 20 for both the experimentals and controls. Although statistically appropriate, this resulted in a number of instances whereby the experimentals and controls differed statistically in size at the onset of the experimentation; this was not realized at the time. Consequently, during the data analysis it was very difficult to compare growth of experimentals and controls. In hindsight, a more appropriate technique would have been to match seedlings at the onset.

In order to analyze the data a posteri, control and experimental samples were compared and individuals were excluded until the samples were statistically alike in terms of means, standard deviations and ranges of initial stem length. Growth parameters (e.g. initial stem length, post stem length, stem weight, root weight, needle weight, initial branching and post branching) of experimentals were then compared to controls.

Means were compared using one way ANOVA techniques and regression lines were fit using linear and curvilinear least squares techniques.

\section{RESULTS}

Fumigation of Germinating Seeds - Most of the seeds $(86.5 \%$ of controls, $84.7 \%$ of experimentals) germinated in the fumigation chambers and grew during the five week experiments. This high germination frequency provided confidence in the experimental design and results. The responses of the experimental seeds were similar to the controls (Table 2). There were no statistical differences between the root-shoot lengths of seeds fumigated at $0.2 \mathrm{ppm}$ and controls $(\mathrm{F}=0.0320 ; \mathrm{df}=1,1642 ; \mathrm{p}=0.8581$; Tables $\mathrm{A}-1$ and A-2 in Appendix A and summarized in Table A-3). Because biomass of individual seeds was too small for accurate measurement, dry mass per tray was measured (Table A-4 in Appendix A). There were no significant differences between root mass of experimental and control germinating seedlings $(F=1.3758 ; \mathrm{df}=1,15 ; \mathrm{p}=0.2604)$ or between stemneedle mass of experimental and control germinating seedlings $(F=0.0002 ; \mathrm{df}=1,31 ; \mathrm{p}=$ $0.9894)$. 
Chronic Exposure of Emergent Seedlings - A number of growth parameters were measured on the emergent seedlings at 1,2,3, and 4 month intervals (Tables A-5 through A-8 in Appendix A and summarized in Table 3). With minor exceptions there were no differences between experimentals and controls in post-experimental stem length, stem mass, needle mass, root mass or branching (Table 4). At 2 months, there was a statistical difference between mean stem mass of experimentals and controls and at 3 months needle mass and root mass differed between experimentals and controls. In general, there appear to be no consistent effects of sulfur dioxide fumigation at $0.2 \mathrm{ppm}$ for 16 weeks on the emergent seedlings.

Acute Exposure of One-Year Seedlings - No injury was observed below a sulfur dioxide concentration of $3.25 \mathrm{ppm}$ (Table 5). Above this concentration injury increased at an exponential rate (Figure 1). The following polynomial regression curve:

$$
\mathbf{I}=-6.7 \mathrm{~S}+2.9 \mathrm{~S}^{2}-0.6
$$

where $\quad I=$ Number of injured trees

$$
\mathbf{S}=\text { Sulfur dioxide concentration in } \mathrm{ppm}
$$

is statistically significant $\left(\mathrm{p}<0.04, \mathrm{r}^{2}=0.88\right)$ and shows rapidly increasing visible damage above $3.5 \mathrm{ppm}$.

Results of the foliar sulfur analyses (Table 6) show no apparent differences among the control and fumigated seedlings either in terms of fumigation level $(\mathrm{F}=1.2821 ; \mathrm{df}=$ $5,23 ; \mathrm{p}=0.3145)$, time of fumigatio: $(\mathrm{F}=3.0654 ; \mathrm{df}=1,23 ; \mathrm{p}=0.0939)$, or age of needles $(\mathrm{F}=0.3714 ; \mathrm{df}=1,23 ; \mathrm{p}=0.5485)$.

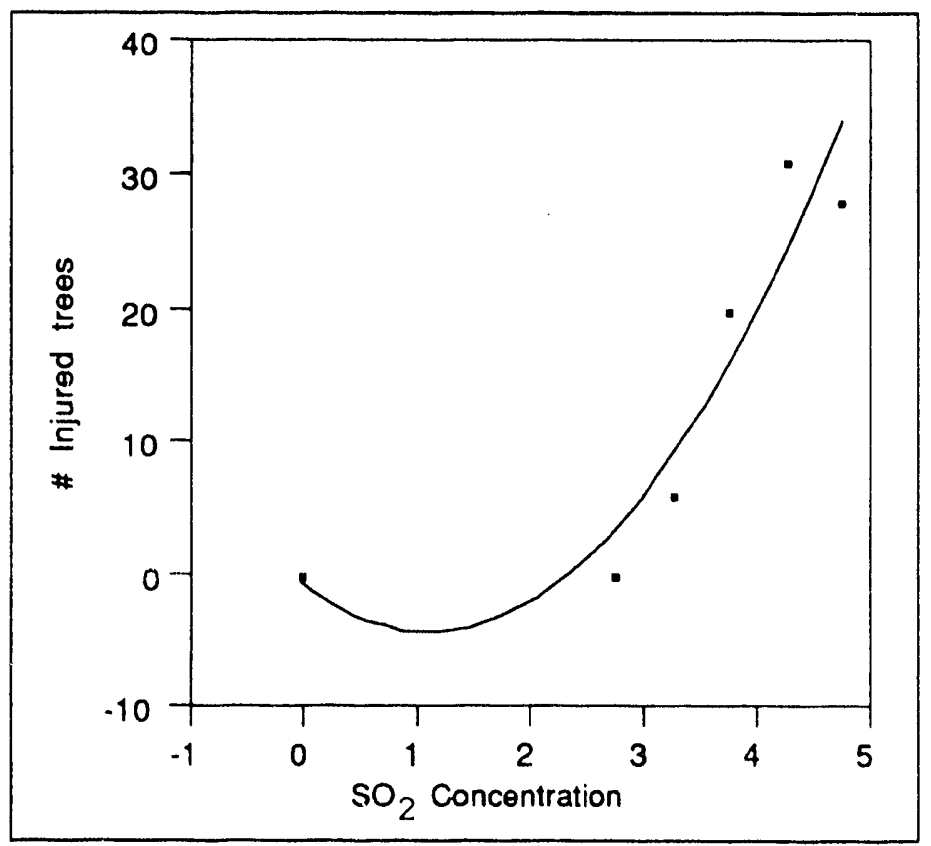

Figure 1. Relationship between injury to Piñon Pine and fumigation levels in ppm $\mathrm{SO}_{2}$. 
Chronic Exposure of One-Year Seedlings - Chronic exposure of one-year seedlings to 0.2 ppm sulfur dioxide also seems to have little effect on the length or mass parameters of the seedlings (Table 7). As none of the experimentals differed significantly from the controls (Table 8), there does not appear to be any effect of the sulfur dioxide fumigation, even at these longer exposure periods. Detailed data compilations of stem length, stem and needle dry weights, and number of branches for individual seedlings fumigated for various time periods ranging from one to four months are found in Appendix A (Tables A-9 through A13).

The foliage sulfur analyses of fumigated seedlings and controls (Table A-14) shows an accumulation of sulfur in the fumigated seedlings during the course of the exposure (Table 9). The sulfur content of fumigated seedlings was significantly different from that of controls for each exposure period. The patterns of accumulation are predictable and interesting (Figure 2). The controls gradually decreased in sulfur content over the 4 month experiment, while the experimental seedlings increased in sulfur content. Although few detrimental effects were seen from the sulfur dioxide fumigation, there was clearly an accumulation of sulfur in the plant tissues.

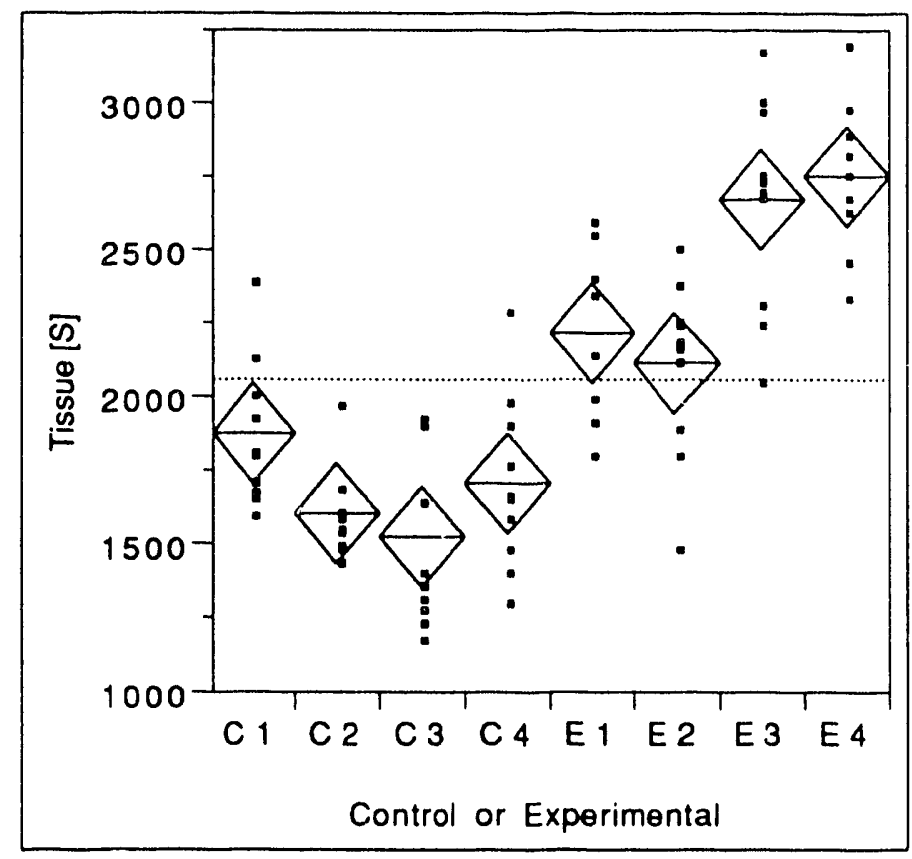

Figure 2. Sulfur concentration in foliage of seedlings exposed for 1, 2, 3 or 4 months. Means are indicated by horizontal lines, $95 \%$ confidence intervais (diamond) and dotted horizontal line indicates grand mean. ( $C=$ control; $E=$ experimentals exposed to $0.2 \mathrm{ppm}$ $\mathrm{SO}_{2}$ for 1-4 months)

Growth Rates of Fumigated and Control Seedlings - The pre- and post-experiment measurements of individual stem lengths give a measure of seedling growth and allow another comparison of the fumigated seedlings with controls. Both the chronic and acute experiments were combined and show a strong linear growth pattern during the experiment. The slopes were similar for both the controls and the experimentals ( 1.07 and 1.11 respectively) and the coefficients of determination ( $\mathrm{r}^{2}$ values) are both high ( 0.98 and 
0.97). This similarity in growth rate is a further indication that there are no observable influences of sulfur dioxide fumigation during the course of the experiments. Because of the growth rate similarity, experimentals and controls were combined to produce the following general growth model (Figure 3):

$$
\mathbf{P}=1.1 \mathrm{I}+1.03
$$

where $\quad \mathbf{P}=$ Post experiment stem length $(\mathrm{mm})$

$$
\mathbf{I}=\text { Initial stem length }(\mathrm{mm})
$$

$$
\left(r^{2}=0.95, p=0.0000\right) \text {. }
$$

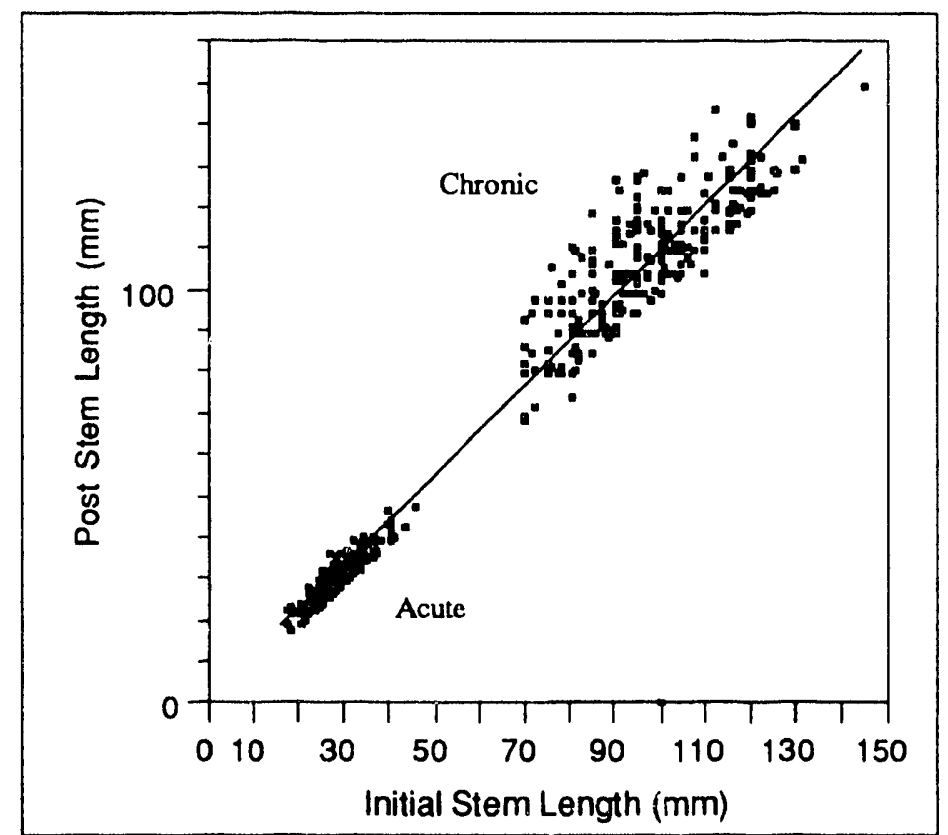

Figure 3. Relationship between pre- and post-experimental stem lengths for both chronic and acute experiments.

\section{DISCUSSION}

An examination of all the data from the Los Alamos study indicates that the only injury or deleterious effect on piñon pine that was observed occurred during acute, 3-h fumigations of one-year seedlings at ambient sulfur dioxide concentrations greater than $3 \mathrm{ppm}$. This injury consisted of visible browning of needles. The conclusion is that piñon pine is very tolerant to sulfur dioxide exposure. This is demonstrated by the lack of effect of fumigation on biomass and other growth parameters of fumigated plants. Furthermore, a growth model of post-fumigation stem length versus pre-fumigation stem length (Figure 3) shows no significant differences between the fit of the experimental seedlings and the control seedlings to this model.

This agrees with results of acute fumigation studies performed by Caldwell et al. (1976) and Hill et al. (1974). Hill et al. exposed piñon pine to various concentrations of sulfur dioxide for two-hour, acute fumigations and recorded zero percent foliar injury at 4 
ppm, 0.06 percent foliar injury at $6 \mathrm{ppm}$, and 2 percent foliar injury at $10 \mathrm{ppm}$. Fumigation at each concentration was replicated several times. These results compare to a somewhat lower injury threshold of $3.25 \mathrm{ppm}$ in the Los Alamos study, but the Los Alamos study used one-year seedlings. The study of Hill et al. apparently used more mature piñon pine trees, which should be less sensitive. The exact age of the piñon pines fumigated by Hill et al. was not specified. Caldwell et al. conducted four-hour fumigations of piñon pine at sulfur dioxide concentrations ranging up to $3.4 \mathrm{ppm}$ over a relative humidity range of 31-54 percent. Results were not reported in terms of percent foliar injury. Instead, the 14 species evaluated in the study were ranked as to relative resistance using a complicated "sensitivity ranking procedure." Piñon pine was determined to be one of the two most resistant species, which agrees with the conclusion of the Los Alamos study. As in the Hill et al. study, Caldwell et al. did noi specify the age of the piñon pine trees used in their study.

No report of chronic sulfur dioxide fumigation of piñon pine could be found in the literature. In the Los Alamos study, chronic fumigation (up to four weeks) was performed at only one ambient sulfur dioxide concentration $(0.2 \mathrm{ppm})$, and no foliar injury was detectable as a result of this exposure. As shown in Table 9 and Figure 2, however, there was a significant increase in foliar sulfur concentration. This is to be expected, as sulfur dioxide is readily taken up through stomata and enters into the sulfur metabolism of the plant (Ziegler, 1975). Deleterious effects are not apparent unless the capacity of the plant to metabolize the excess sulfur into innocuous storage compounds is exceeded.

As most other Pinus species range in sensitivity from extremely sensitive to moderately tolerant to sulfur dioxide exposure, a possible explanation for the high sulfur dioxide tolerance of piñon pine is that it is more xerophytically adapted to desert conditions, possessing thicker epidermal and epicuticular wax layers and being physiologically adapted to shorter periods of stomatal opening. The results of the Los Alamos study indicate that piñon pine is not nearly as likely to be affected by exposure to ambient sulfur dioxide as are other, more sensitive, species. Nonetheless, the foliar damage resulting from high sulfur dioxide levels should ultimately lead to growth differences, although this might take several years to become apparent. 


\section{REFERENCES}

Bower, N.W., E.S. Gladney, and R.W. Ferenbaugh. 1986. Critical comparison of x-ray fluorescence and combustion-infrared methods for the determination of sulfur in biological matrices. Analyst 111: 105-106.

Caldwell, R.L., P.K. Wilson, and R.J. Frye. 1976. A screening stıdy to determine the symptomology and relative susceptibility of selected native trees and shrubs to sulfur dioxide. Unpublished Project Report to U.S. Forest Service. University of Arizona. Tucson. $75 \mathrm{pp}$.

Davis, C.R., D.R. Howell, and G.W. Morgan. 1966. Sulphur dioxide fumigations of range grasses native to southeastern Arizona. J. Range Man. 19: 60-64.

Ferenbaugh, R.W. 1978. Effects of prolonged exposure of Oryzopsis hymenoides to $\mathrm{SO}_{2}$. Water Air Soil Pollut. 10: 27-31.

Ferenbaugh, R.W., W.S. Gaud, and J.S. States. 1979. Pollutant sorption by desert soils. Bull. Environ. Contam. Toxicol. 22: 681-687.

Gautier, M.A., E.S. Gladney, M.B. Phillips, and B.T. O'Malley. 1989. Quality Assurance for Health and Environmental Chemistry: 1988. Report No. LA-11637-MS. Los Alamos National Laboratory. Los Alamos, New Mexico. 479 pp.

Gladney, E.S., R. Raymond, and N.W. Bower. 1985. An analyzer for the determination of sulfur in coals and peats. Amer. Lab. 17(7): 34-37.

Gladney, E.S., R.W. Ferenbaugh, R.G. Bowker, E.A. Jones, M.G. Bell, J.D. Morgan, E.A. Stallings, L.A. Nelson, and C. Lundstrom. 1993a. An investigation of sulfur concentrations in soils and pine needles in Bandelier National Monument, New Mexico. Report No. LA-12417-MS. Los Alamos National Laboratory. Los Alamos, New Mexico. $48 \mathrm{pp}$.

Gladney, E.S., R.W. Ferenbaugh, R.G. Bowker, E.A. Jones, M.G. Bell, J.D. Morgan, L.A. Nelson, and C. Lundstrom. 1993b. An investigation of sulfur concentrations in soils and pine needles in Canyonlands National Park, Utah. Report No. LA-12418-MS. Los Alamos National Laboratory. Los Alamos, New Mexico. 46 pp.

Gladney, E.S., R.W. Ferenbaugh, R.G. Bowker, E.A. Jones, M.G. Bell, J.D. Morgan, and L.A. Nelson. 1993c. An investigation of sulfur concentrations in soils and pine needles in Chaco Culture National Historical Park, New Mexico. Report No. LA-12419MS. Los Alamos National Laboratory. Los Alamos, New Mexico. 46 pp.

Gladney, E.S., R.W. Ferenbaugh, R.G. Bowker, E.A. Jones, M.G. Bell, J.D. Morgan, L.A. Nelson, and C. Lundstrom. 1993d. An investigation of sulfur concentrations in soils and pine needles in Mesa Verde National Park, Colorado. Report No. LA-12420MS. Los Alamos Nátional Laboratory. Los Alamos, New Mexico. 48 pp. 
Gladney, E.S., R.W. Ferenbaugh, R.G. Bowker, E.A. Stallings, E.A. Jones, L.M. Candelaria, L.A. Nelson, and C. Lundstrom. 1993e. An investigation of sulfur concentrations in soils and pine needles on Chinde Mesa, Petrified Forest National Park, Arizona. Report No. LA-12421-MS. Los Alamos National Laboratory. Los Alamos, New Mexico. $47 \mathrm{pp}$.

Heck, W.W., R.B. Philbeck, and J.A. Dunning. 1978. A continuous stirred tank reactor (CSTR) system for exposing plants to gaseous air contaminants. Report No. ARS-S-181. Agricultural Research Service. Raleigh, North Carolina. 29 pp.

Hill, A.C., S. Hill, C. Lamb, and T.W. Barrett. 1974. Sensitivity of native desert vegetation to $\mathrm{SO}_{2}$ and $\mathrm{SO}_{2}$ and $\mathrm{NO}_{2}$ combined. APCA Journal 24: 153-157.

Johnson, Z.O. 1974. The effects of $\mathrm{SO}_{2}$ on three desert grasses. M.S. Thesis. Northern Arizona University. Flagstaff, Arizona. $48 \mathrm{pp}$.

Thompson, C.R., G. Kats, and R.W. Lennox. 1980. Effects of $\mathrm{SO}_{2}$ and/or $\mathrm{NO}_{2}$ on native plants of the Mojave Desert and eastern Mojave-Colorado Desert. APCA Journal 30: 1304-1309.

Thompson, C.R., D.M. Olszyk, G. Kats, A. Bytnerowicz, P.J. Dawson, and J.W. Wolf. 1984. Effects of ozone or sulfur dioxide on annual plants of the Mojave Desert. APCA Journal 34: 1017-1022.

Ziegler, I. 1975. The effect of $\mathrm{SO}_{2}$ pollution on plant metabolism. Residue Rev. 56: 79105. 
Table 1. Acute exposure schedule. Concentration of $\mathrm{SO}_{2}(\mathrm{ppm})$ assigned to different chambers in different fumigations.

\begin{tabular}{ccccc} 
& \multicolumn{2}{c}{ AM-1 } & \multicolumn{2}{c}{ PM-2 } \\
Day & Chamber 1 & Chamber 2 & Chamber 1 & Chamber 2 \\
\hline & & & & \\
2 & 3.25 & 4.75 & 2.75 & 0.00 \\
3 & 4.75 & 0.00 & 4.25 & 3.25 \\
4 & 2.75 & 4.25 & 0.00 & 3.75 \\
5 & 4.25 & 2.75 & 4.25 & 0.00 \\
6 & 2.75 & 3.75 & 3.75 & 4.75 \\
7 & 0.00 & 3.75 & 2.75 & 3.75 \\
8 & 4.25 & 4.75 & 0.00 & 2.75 \\
9 & 3.75 & 0.00 & 4.75 & 3.25 \\
10 & 3.25 & 3.75 & 3.25 & 4.75 \\
11 & 3.25 & 4.25 & 4.75 & 2.75 \\
12 & 2.75 & 0.00 & 3.75 & 4.75 \\
13 & 4.75 & 2.75 & 2.75 & 3.25 \\
14 & 4.75 & 4.25 & 3.25 & 4.25 \\
15 & 3.75 & 4.25 & 0.00 & 3.25 \\
& 0.00 & 4.25 & 3.75 & 3.25
\end{tabular}

Table 2. Summary of seed germination data.

EXPERIMENTAL CONTROL

No. Seeds Sown

No. Seeds Germinated

$\%$ Germinated

960

960

$813 \quad 830$

Root-Shoot Length (mm)

$84.7 \quad 86.5$

Mean Length

SD

26.7

26.6

Min. Length

Max. Length

4.95

5.01

11

10

$53 \quad 46$

Total Dry Weight (g)

66.3

66.2 


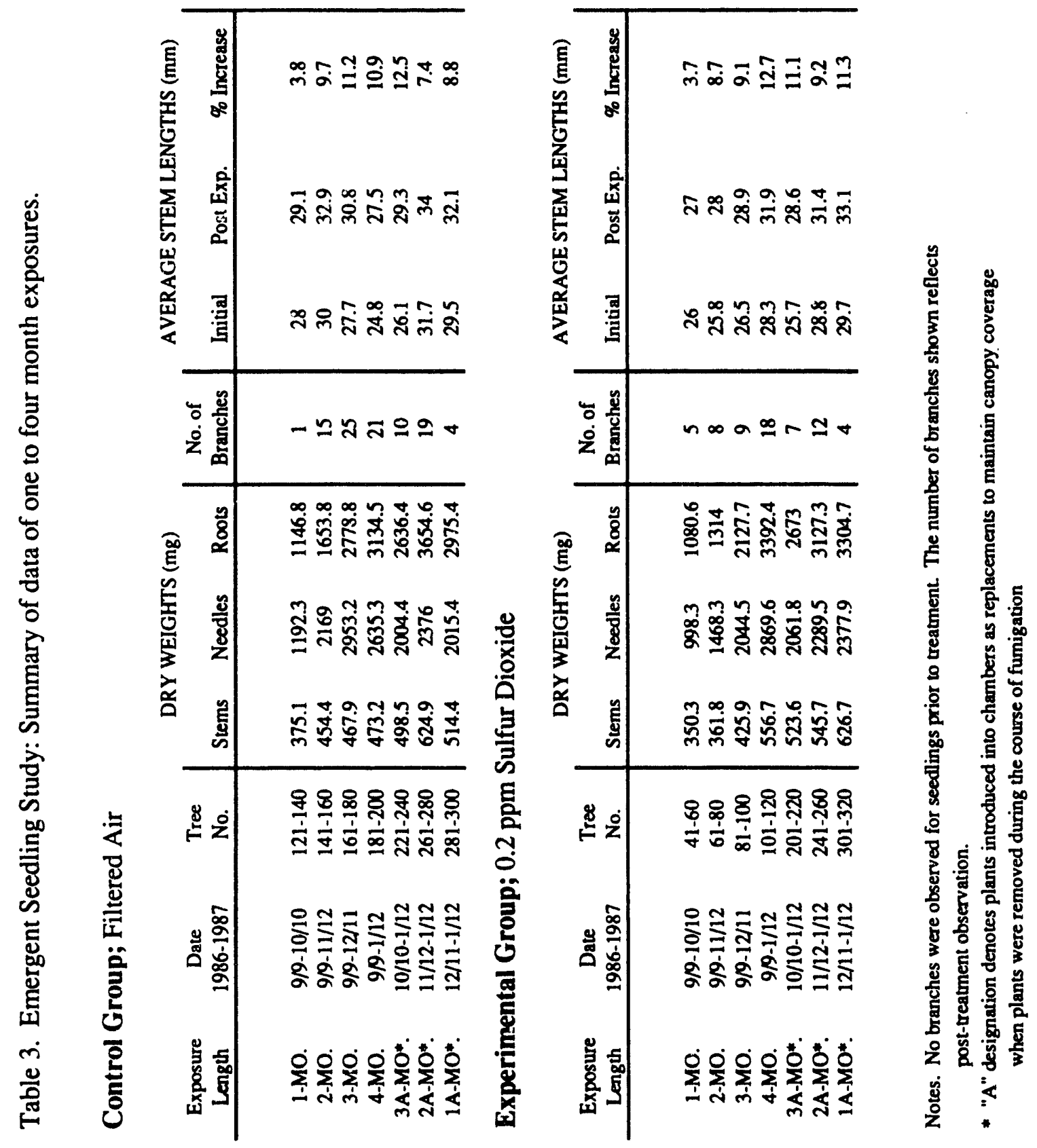


Table 4. Comparison of various plant growth parameters between controls and experimentals for various fumigation periods in the Emergent Seedling Study.

\begin{tabular}{cccccccc}
$\begin{array}{c}\text { Fumigation } \\
\text { Period }\end{array}$ & $\begin{array}{c}\text { Initial Stem } \\
\text { Length }\end{array}$ & $\begin{array}{c}\text { Post Stem } \\
\text { Length }\end{array}$ & $\begin{array}{c}\text { Stem } \\
\text { Mass }\end{array}$ & $\begin{array}{c}\text { Needle } \\
\text { Mass }\end{array}$ & $\begin{array}{c}\text { Root } \\
\text { Mass }\end{array}$ & $\begin{array}{c}\text { Initial Branch } \\
\text { Number }\end{array}$ & $\begin{array}{c}\text { Post Branch } \\
\text { Number }\end{array}$ \\
\hline 1 Month & $\mathrm{ns}$ & $\mathrm{ns}$ & $\mathrm{ns}$ & $\mathrm{ns}$ & $\mathrm{ns}$ & $\mathrm{ns}$ & $\mathrm{ns}$ \\
2 Months & $\mathrm{ns}$ & $\mathrm{ns}$ & $\mathrm{p}<0.04$ & $\mathrm{~ns}$ & $\mathrm{~ns}$ & $\mathrm{~ns}$ & $\mathrm{~ns}$ \\
$\mathbf{3}$ Months & $\mathrm{ns}$ & $\mathrm{ns}$ & $\mathrm{ns}$ & $\mathbf{p}<0.008$ & $\mathbf{p}<0.03$ & $\mathrm{~ns}$ & $\mathrm{~ns}$ \\
4 Months & $\mathrm{ns}$ & $\mathrm{ns}$ & $\mathrm{ns}$ & $\mathrm{ns}$ & $\mathrm{ns}$ & $\mathrm{ns}$ & $\mathrm{ns}$ \\
All & $\mathrm{ns}$ & $\mathrm{ns}$ & $\mathrm{ns}$ & $\mathrm{ns}$ & $\mathrm{ns}$ & $\mathrm{ns}$ & $\mathrm{ns}$
\end{tabular}




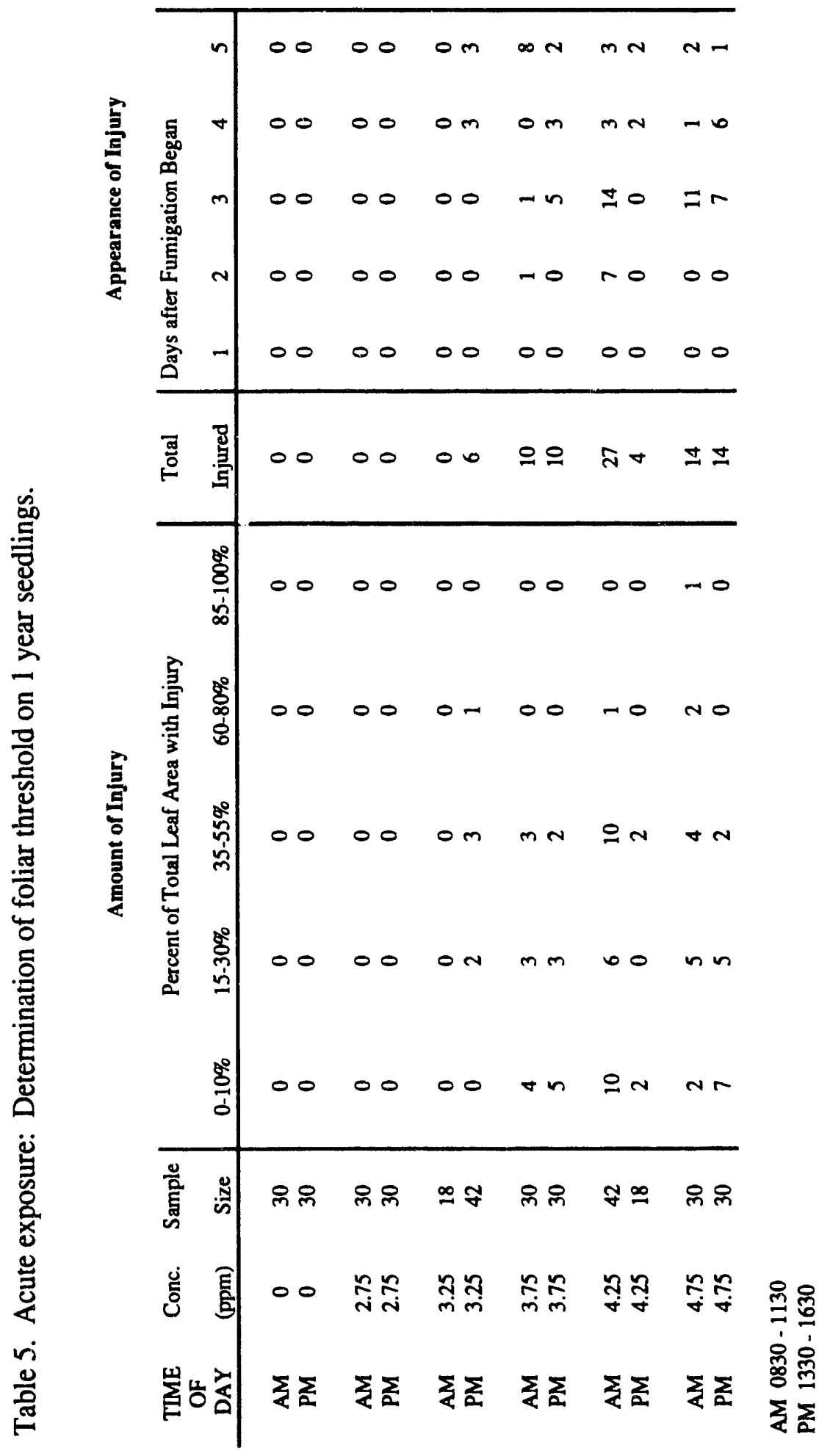


Table 6. Acute Fumigation Sulfur Data.

\begin{tabular}{|c|c|c|c|}
\hline $\begin{array}{c}\text { Fumigation } \\
\mathrm{SO}_{2} \text { Conc. (ppm) }\end{array}$ & Time & Needles & $\begin{array}{c}\text { Foliar } \\
\text { Sulfur Conc. (ppm) } \\
\end{array}$ \\
\hline \multirow[t]{3}{*}{ Control } & $\mathrm{AM}$ & old & $\begin{array}{r}1990 \pm 100 \\
1870+90\end{array}$ \\
\hline & PM & old & $1880 \pm 90$ \\
\hline & & new & $1850 \pm 90$ \\
\hline \multirow[t]{4}{*}{2.75} & $\mathrm{AM}$ & old & $1930 \pm 90$ \\
\hline & & new & $1970 \pm 100$ \\
\hline & PM & old & $1900 \pm 90$ \\
\hline & & new & $870 \pm 90$ \\
\hline \multirow[t]{4}{*}{3.25} & $\mathrm{AM}$ & old & $1800 \pm 90$ \\
\hline & & new & $1780 \pm 90$ \\
\hline & PM & old & $1920 \pm 90$ \\
\hline & & new & $1920 \pm 90$ \\
\hline \multirow[t]{4}{*}{3.75} & $\mathrm{AM}$ & old & $1990 \pm 100$ \\
\hline & & new & $2010 \pm 100$ \\
\hline & $P$ M & old & $1920 \pm 90$ \\
\hline & & new & $890 \pm 90$ \\
\hline \multirow[t]{4}{*}{4.25} & $\mathrm{AM}$ & old & $2050 \pm 100$ \\
\hline & & new & $040 \pm 100$ \\
\hline & PM & old & $880 \pm 90$ \\
\hline & & new & $1830 \pm 90$ \\
\hline \multirow[t]{4}{*}{4.75} & $\mathrm{AM}$ & old & $1880 \pm 90$ \\
\hline & & new & $1890 \pm 90$ \\
\hline & PM & old & $1880 \pm 90$ \\
\hline & & new & $1890 \pm 90$ \\
\hline
\end{tabular}




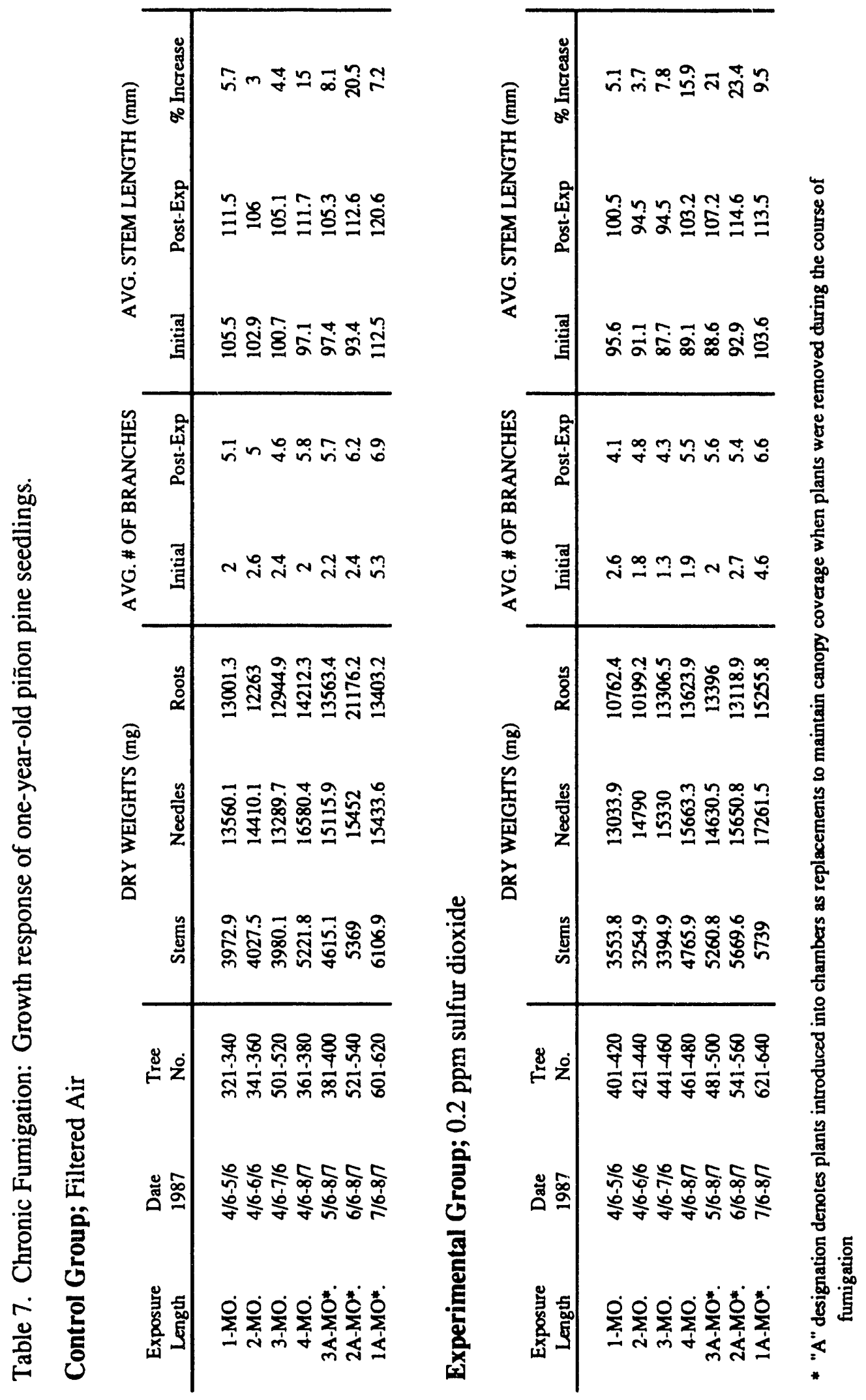


Table 8. Comparison of various plant growth parameters between controls and experimentals for various fumigation periods in the Chronic Fumigation Study.

\begin{tabular}{cccccccc}
$\begin{array}{c}\text { Exposure } \\
\text { Length }\end{array}$ & $\begin{array}{c}\text { Initial Stem } \\
\text { Length }\end{array}$ & $\begin{array}{c}\text { Post Stem } \\
\text { Length }\end{array}$ & $\begin{array}{c}\text { Stem } \\
\text { Mass }\end{array}$ & $\begin{array}{c}\text { Needle } \\
\text { Mass }\end{array}$ & $\begin{array}{c}\text { Root } \\
\text { Mass }\end{array}$ & $\begin{array}{c}\text { Initial Branch } \\
\text { Number }\end{array}$ & $\begin{array}{c}\text { Post Branch } \\
\text { Number }\end{array}$ \\
\hline 1 Month & $\mathrm{ns}$ & $\mathrm{ns}$ & $\mathrm{ns}$ & $\mathrm{ns}$ & $\mathrm{ns}$ & $\mathrm{ns}$ & $\mathrm{ns}$ \\
2 Months & $\mathrm{ns}$ & $\mathrm{ns}$ & $\mathrm{ns}$ & $\mathrm{ns}$ & $\mathrm{ns}$ & $\mathrm{ns}$ & $\mathrm{ns}$ \\
$\mathbf{3}$ Months & $\mathrm{ns}$ & $\mathrm{ns}$ & $\mathrm{ns}$ & $\mathrm{ns}$ & $\mathrm{ns}$ & $\mathrm{ns}$ & $\mathrm{ns}$ \\
4 Months & $\mathrm{ns}$ & $\mathrm{ns}$ & $\mathrm{ns}$ & $\mathrm{ns}$ & $\mathrm{ns}$ & $\mathrm{ns}$ & $\mathrm{ns}$
\end{tabular}

Table 9. Summary of chronic fumigation sulfur data. Mean values $( \pm 1$ SD) for controls and for $\mathrm{SO}_{2}$ fumigations for $1,2,3$ and 4 months. Probability values show significance levels for comparison of each pair of means.

\begin{tabular}{cccc} 
& \multicolumn{2}{c}{ AVERAGE FOLIAR SULFUR CONCENTRATION (ppm) } & \\
\cline { 2 - 3 } $\begin{array}{c}\text { Exposure } \\
\text { Length }\end{array}$ & Control & $0.2 \mathrm{ppm} \mathrm{SO}{ }_{2}$ & $\mathrm{p}=$ \\
\hline & $1881 \pm 247.8$ & $2226 \pm 279.8$ & 0.0092 \\
1 month & $1606 \pm 149.5$ & $2116 \pm 300.7$ & 0.0001 \\
2 month & $1526 \pm 300.4$ & $2675 \pm 360.5$ & 0.0000 \\
3 month & $1716 \pm 294.5$ & $2755 \pm 249.6$ & 0.0000 \\
4 month & & &
\end{tabular}


APPENDIX A:

Fumigation Data 
TABLE A-1: Seed Germination Study, Root-Shoot Lengths, Control Seeds

COWIROL GROUP, PART

CONTROL GROUP, PART 2

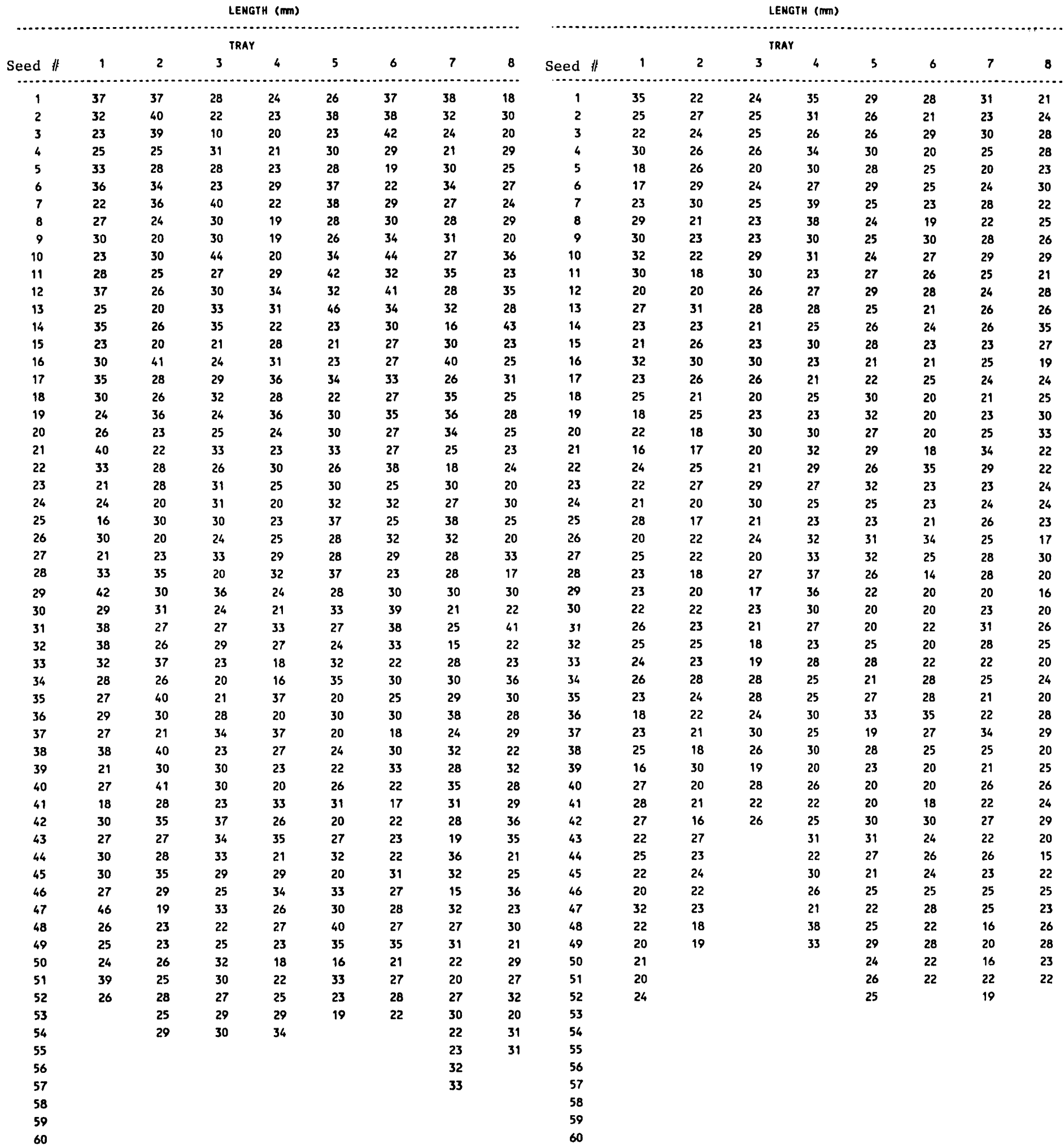


TABLE A-2: Seed Germination Study, Root-Shoot Lengths, Fumigated Seeds

IXPERIMENTAL GROUP, PART 1

EXPERIMENTAL GROUP, PART 2

LENGTH $(\mathrm{mm})$

LENGTH (mm)

\begin{tabular}{|c|c|c|c|c|c|c|c|c|c|c|c|c|c|c|c|c|c|}
\hline \multicolumn{9}{|c|}{ TRAY } & \multicolumn{9}{|c|}{ TRAY } \\
\hline Seed \# & 1 & 2 & 3 & 4 & 5 & 6 & 7 & 8 & Seed \# & 1 & 2 & 3 & 4 & 5 & 6 & 7 & 8 \\
\hline 1 & 36 & 30 & 28 & 22 & 35 & 22 & 26 & 27 & 1 & 30 & 23 & 18 & 25 & 30 & 19 & 26 & 21 \\
\hline 2 & 37 & 36 & 28 & 29 & 24 & 30 & 32 & 35 & 2 & 28 & 20 & 25 & 22 & 22 & 22 & 20 & 23 \\
\hline 3 & 32 & 30 & 36 & 29 & 22 & 32 & 23 & 30 & 3 & 21 & 20 & 23 & 22 & 21 & 18 & 20 & 21 \\
\hline 4 & 37 & 31 & 35 & 34 & 31 & 30 & 24 & 30 & 4 & 22 & 18 & 30 & 22 & 17 & 20 & 18 & 22 \\
\hline 5 & 36 & 30 & 30 & 31 & 22 & 45 & 35 & 25 & 5 & 21 & 24 & 24 & 24 & 20 & 25 & 24 & 20 \\
\hline 6 & 42 & 35 & 28 & 26 & 21 & 30 & 34 & 32 & 6 & 23 & 30 & 21 & 18 & 23 & 24 & 17 & 24 \\
\hline 7 & 31 & 24 & 39 & 25 & 19 & 26 & 24 & 35 & 7 & 22 & 25 & 25 & 24 & 31 & 20 & 24 & 21 \\
\hline 8 & 27 & 27 & 33 & 30 & 34 & 27 & 37 & 28 & 8 & 30 & 18 & 25 & 26 & 24 & 23 & 23 & 23 \\
\hline 9 & 40 & 23 & 23 & 31 & 27 & 28 & 32 & 27 & 9 & 17 & 23 & 20 & 23 & 25 & 23 & 21 & 20 \\
\hline 10 & 40 & 24 & 28 & 33 & 22 & 38 & 35 & 20 & 10 & 20 & 21 & 23 & 23 & 20 & 23 & 23 & 18 \\
\hline 11 & 23 & 21 & 25 & 17 & 35 & 15 & 34 & 26 & 11 & 28 & 20 & 25 & 26 & 26 & 16 & 26 & 30 \\
\hline 12 & 31 & 15 & 29 & 28 & 30 & 36 & 22 & 36 & 12 & 27 & 33 & 22 & 22 & 21 & 23 & 19 & 24 \\
\hline 13 & 25 & 18 & 31 & 28 & 34 & 27 & 43 & 30 & 13 & 27 & 26 & 15 & 22 & 15 & 21 & 22 & 28 \\
\hline 14 & 25 & 35 & 32 & 25 & 21 & 21 & 32 & 46 & 14 & 26 & 23 & 21 & 20 & 28 & 21 & 19 & 25 \\
\hline 15 & 37 & 29 & 33 & 22 & 30 & 35 & 30 & 26 & 15 & 23 & 19 & 16 & 23 & 21 & 20 & 25 & 25 \\
\hline 16 & 25 & 20 & 18 & 32 & 29 & 33 & 35 & 30 & 16 & 24 & 20 & 35 & 20 & 26 & 17 & 17 & 19 \\
\hline 17 & 36 & $2 B$ & 29 & 30 & 29 & 32 & 28 & 18 & 17 & 24 & 20 & 21 & 20 & 21 & 21 & 21 & 25 \\
\hline 18 & 39 & 23 & 29 & 29 & 25 & 28 & 25 & 29 & 18 & 28 & 21 & 20 & 25 & 24 & 20 & 17 & 23 \\
\hline 19 & 31 & 33 & 27 & 30 & 38 & 27 & 35 & 17 & 19 & 30 & 18 & 24 & 21 & 22 & 23 & 23 & 24 \\
\hline 20 & 47 & 25 & 19 & 28 & 32 & 29 & 33 & 29 & 20 & 27 & 16 & 22 & 25 & 18 & 19 & 26 & 22 \\
\hline 21 & 27 & 27 & 33 & 26 & 31 & 44 & 25 & 30 & 21 & 25 & 24 & 24 & 17 & 22 & 14 & 26 & 28 \\
\hline 22 & 46 & 39 & 28 & 34 & 35 & 42 & 21 & 31 & 22 & 32 & 25 & 23 & 20 & 23 & 16 & 20 & 24 \\
\hline 23 & 43 & 27 & 25 & 33 & 25 & 41 & 40 & 24 & 23 & 21 & 23 & 14 & 23 & 23 & 20 & 23 & 20 \\
\hline 24 & 32 & 24 & 30 & 33 & 21 & 38 & 30 & 44 & 24 & 24 & 21 & 22 & 20 & 20 & 25 & 24 & 27 \\
\hline 25 & 32 & 40 & 40 & 32 & 28 & 28 & 31 & 32 & 25 & 22 & 22 & 24 & 23 & 32 & 20 & 24 & 18 \\
\hline 26 & 20 & 32 & 20 & 18 & 35 & 30 & 35 & 20 & 26 & 20 & 27 & 27 & 26 & 20 & 22 & 19 & 16 \\
\hline 27 & 28 & 28 & 38 & 35 & 45 & 21 & 33 & 26 & 27 & 22 & 21 & 25 & 17 & 23 & 20 & 24 & 19 \\
\hline 28 & 40 & 33 & 15 & 34 & 39 & 32 & 32 & 37 & 28 & 28 & 18 & 22 & 19 & 19 & 27 & 11 & 22 \\
\hline 29 & 39 & 34 & 30 & 35 & 32 & 26 & 31 & 23 & 29 & 17 & 21 & 21 & 18 & 24 & 19 & 20 & 27 \\
\hline 30 & 37 & 21 & 34 & 24 & 22 & 36 & 25 & 28 & 30 & 21 & 20 & 23 & 20 & 33 & 21 & 15 & 26 \\
\hline 31 & 38 & 25 & 22 & 35 & 27 & 32 & 42 & 30 & 31 & 30 & 24 & 15 & 22 & 31 & 21 & 18 & 16 \\
\hline 32 & 40 & 48 & 28 & 21 & 41 & 28 & 26 & 25 & 32 & 23 & 20 & 27 & 20 & 24 & 28 & 22 & 21 \\
\hline 33 & 25 & 36 & 28 & 33 & 30 & 29 & 29 & 31 & 33 & 20 & 20 & 15 & 20 & 25 & 20 & 26 & 27 \\
\hline 34 & 39 & 37 & 30 & 44 & 28 & 32 & 28 & 37 & 34 & 25 & 25 & 24 & 20 & 19 & 25 & 20 & 16 \\
\hline 35 & 21 & 33 & 26 & 36 & 42 & 28 & 34 & 28 & 35 & 30 & 23 & 20 & 23 & 23 & 24 & 27 & 22 \\
\hline 36 & 23 & 34 & 35 & 27 & 35 & 24 & 31 & 28 & 36 & 24 & 25 & 22 & 23 & 25 & 23 & 22 & 21 \\
\hline 37 & 44 & 44 & 34 & 26 & & 26 & 35 & 45 & 37 & 22 & 16 & 19 & 18 & 23 & 21 & 21 & 20 \\
\hline 38 & 32 & 26 & 29 & 34 & & 28 & 27 & 32 & 38 & 26 & 33 & 20 & 21 & 26 & 17 & 18 & 27 \\
\hline 39 & 31 & 24 & 36 & 34 & & 12 & 30 & 30 & 39 & 26 & 19 & 16 & 17 & 23 & 22 & 23 & 20 \\
\hline 40 & 28 & 37 & 28 & 36 & & 29 & 31 & 35 & 40 & 22 & 28 & 17 & 21 & 27 & 16 & 32 & 31 \\
\hline 41 & 32 & 35 & 34 & 32 & & 37 & 46 & 40 & 41 & 27 & 21 & 24 & 24 & 19 & 24 & 22 & 27 \\
\hline 42 & 23 & 23 & 34 & 25 & & 34 & 23 & 33 & 42 & 20 & 25 & 31 & 25 & 17 & 21 & 25 & 32 \\
\hline 43 & 29 & 39 & 24 & 37 & & 23 & 39 & 33 & 43 & 25 & 30 & 25 & 29 & 32 & 12 & 20 & 25 \\
\hline 44 & 29 & 37 & 25 & 32 & & 34 & 28 & 28 & 44 & 25 & 22 & 20 & 21 & 18 & 19 & 15 & 21 \\
\hline 45 & 37 & 31 & 27 & 29 & & 28 & 32 & 33 & 45 & 24 & 23 & 35 & 20 & 25 & 18 & 18 & 21 \\
\hline 46 & 28 & 34 & 25 & 40 & & 22 & & 40 & 46 & 25 & 24 & 25 & 25 & 23 & 20 & 18 & 18 \\
\hline 47 & 35 & 42 & 28 & 30 & & & & 24 & 47 & 26 & 22 & 23 & 28 & 23 & & 15 & 25 \\
\hline 48 & 36 & 33 & 35 & 30 & & & & 43 & 48 & 22 & 18 & 21 & 23 & 23 & & & 23 \\
\hline 49 & 40 & 32 & 31 & 33 & & & & 31 & 49 & 19 & 21 & 24 & 21 & 22 & & & 22 \\
\hline 50 & 45 & 35 & 33 & 37 & & & & 37 & 50 & 19 & 22 & 22 & 30 & 18 & & & 20 \\
\hline 51 & 25 & 29 & 42 & 30 & & & & 29 & 51 & 29 & 20 & 19 & 25 & 23 & & & 20 \\
\hline 52 & 26 & & 22 & 37 & & & & 38 & 52 & 23 & & & 20 & 22 & & & 19 \\
\hline 53 & 53 & & 30 & 42 & & & & & 53 & 32 & & & 22 & 21 & & & 28 \\
\hline 54 & 37 & & 32 & 37 & & & & & 54 & 23 & & & 21 & 21 & & & 21 \\
\hline 55 & 34 & & 35 & & & & & & 55 & 22 & & & 16 & 26 & & & 23 \\
\hline 56 & & & 42 & & & & & & 56 & & & & 21 & & & & \\
\hline 57 & & & 32 & & & & & & 57 & & & & & & & & \\
\hline 58 & & & 30 & & & & & & 58 & & & & & & & & \\
\hline 59 & & & & & & & & & 59 & & & & & & & & \\
\hline 60 & & & & & & & & & 60 & & & & & & & & \\
\hline
\end{tabular}


TABLE A-3: Seed Germination Study, Root-Shoot Lengths, Data Summary

STATISTICAL ANALYSIS: CONTROL GROUP, PART 1.

TRAY 1 TRAY 2 TRAY 3 TRAY 4 TRAY 5 TRAY 6 TRAY 7 TRAY 8 TOTALS

\begin{tabular}{|c|c|c|c|c|c|c|c|c|c|}
\hline NO.SEEDS SONN & 60 & 60 & 60 & 60 & 60 & 60 & 60 & 60 & 480 \\
\hline NO.GERMINATED & 52 & 54 & 54 & 54 & 53 & 53 & 57 & 55 & 432 \\
\hline XGERMINATED & 86.7 & 90.0 & 90.0 & 90.0 & 88.3 & 88.3 & 95.0 & 91.7 & 90.0 \\
\hline MEAN & 29.3 & 28.7 & 28.3 & 26.1 & 29.1 & 29.2 & 28.5 & 27.4 & 28.3 \\
\hline STO & 6.29 & 6.14 & 5.61 & 5.56 & 6.39 & 6.18 & 5.84 & 5.71 & 5.97 \\
\hline MIN. LENGTH & 16 & 19 & 10 & 16 & 16 & 17 & 15 & 17 & 10 \\
\hline MAX. LENGTH & 46 & 41 & 44 & 37 & 46 & 44 & 40 & 43 & 46 \\
\hline
\end{tabular}

STATISTICAL ANALYSIS: CONTROL GROUP, PART 2.

TOTALS

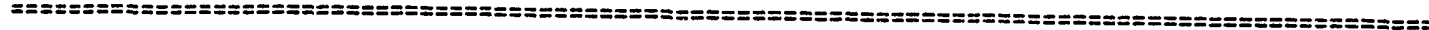
NO. GERMINATED 60

60

$============$

\section{XGERMINATED}

MEAN

STO

MIN. LENGTH

52

60

86.7

49

42

60

60

23.9

81.7

70.0

49

60
52

81.7

86.7

$23.0 \quad 24.3$

28.3

25.9

4.26

3.76

3.67

4.79

3.60

20

MAX. LENGTH

35

31

30

39

19

60

51

85.0

24.0

4.36

14

$33 \quad 35$

$\begin{array}{rrr}60 & 60 & 480 \\ 52 & 51 & 398 \\ 86.7 & 85.0 & 82.9 \\ 24.6 & 24.4 & 24.8 \\ 3.77 & 4.08 & 4.04 \\ 16 & 15 & 14 \\ 34 & 35 & 39\end{array}$

STATISTICAL ANALYSIS: EXPERIMENTAL GROUP, PART 1.

TRAY 1 TRAY 2 TRAY 3 TRAY 4 TRAY 5 TRAY 6 TRAY 7 TRAY 8 TOTALS

\begin{tabular}{|c|c|c|c|c|c|c|c|c|c|}
\hline NO.SEEDS SOWN & 60 & 60 & 60 & 60 & 60 & 60 & 60 & 60 & 480 \\
\hline NO. GERMINATED & 55 & 51 & 58 & 54 & 36 & 46 & 45 & 52 & 397 \\
\hline \%GERMINATED & 91.7 & 85.0 & 96.7 & 90.0 & 60.0 & 76.7 & 75.0 & 86.7 & 82.7 \\
\hline MEAN & 33.7 & 30.5 & 29.8 & 30.7 & 29.9 & 30.3 & 31.2 & 30.8 & 30.9 \\
\hline STO & 7.24 & 6.79 & 5.56 & 5.45 & 6.53 & 6.13 & 5.62 & 6.43 & 6.22 \\
\hline MIN. LENGTH & 20 & 15 & 15 & 17 & 19 & 15 & 21 & 17 & 15 \\
\hline MAX. LENGTH & 53 & 48 & 42 & 44 & 45 & 45 & 46 & 46 & 53 \\
\hline
\end{tabular}

STATISTICAL ANALYSIS: EXPERIMENTAL GROUP, PART 2.

TOTALS

\begin{tabular}{|c|c|c|c|c|c|c|c|c|c|}
\hline NO.SEEDS SOWN & 60 & 60 & 60 & 60 & 60 & 60 & 60 & 60 & 480 \\
\hline NO.GERMINATED & 55 & 51 & 51 & 56 & 55 & 46 & 47 & 55 & 416 \\
\hline XGERMINATED & 91.7 & 85.0 & 85.0 & 93.3 & 91.7 & 76.7 & 78.3 & 91.7 & 86.7 \\
\hline MEAN & 24.3 & 22.4 & 22.4 & 22.0 & 23.1 & 20.7 & 21.3 & 22.7 & 22.4 \\
\hline Sro & 3.65 & 3.76 & 4.40 & 2.96 & 3.95 & 3.17 & 3.86 & 3.69 & 3.68 \\
\hline MIN. LENGTH & 17 & 16 & 14 & 16 & 15 & 12 & 11 & 16 & 11 \\
\hline MAX. I.ENGTH & 32 & 33 & 35 & 30 & 33 & 28 & 32 & 32 & \\
\hline
\end{tabular}


TABLE A-4: Seed Germination Study, Dry Weight Data

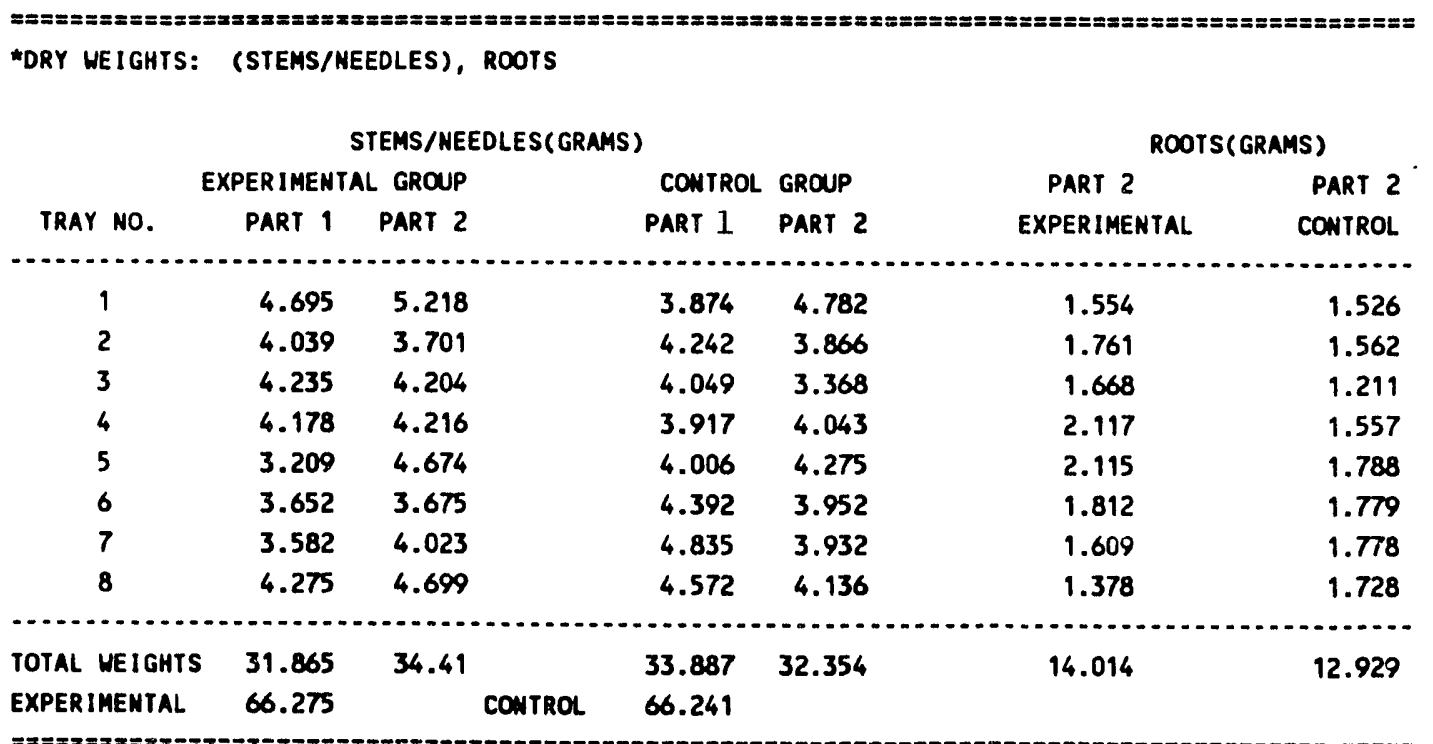

* DRY WEIGHTS FOR ROOTS, PART 1, EXPERIAENTAL \& CONTROL GROUPS WERE NOT OBTAINED 
TABLE A-5: Emergent Seedling Study, 1-Month Exposure Data

CONTROL

\begin{tabular}{|c|c|c|c|c|c|c|}
\hline \multirow[b]{2}{*}{ TREE NO. } & STEM LENGT & $H(m)$ & DRY & WEIGHTS & (mg) & \multirow[b]{2}{*}{$\begin{array}{l}\text { NO. OF } \\
\text { BRAMCHES }\end{array}$} \\
\hline & INITIAL & POST -EXP. & STEMS & MEEDLES & ROOTS & \\
\hline & & & & & & \\
\hline 121 & 28 & 30 & 22.8 & 75.1 & & 0 \\
\hline 122 & 23 & 24 & 17.1 & 36.5 & & 0 \\
\hline 123 & 31 & 32 & 20.9 & 80.5 & & 0 \\
\hline 124 & 21 & 22 & 13.5 & 51.9 & & 0 \\
\hline 125 & 32 & 32 & 23.4 & 71.9 & & 0 \\
\hline 126 & 32 & 33 & 22.1 & 42.7 & & 0 \\
\hline 127 & 27 & 27 & 20.4 & 32.3 & & 0 \\
\hline 128 & 45 & 48 & 28.1 & 110.0 & & 1 \\
\hline 129 & 26 & 27 & 19.0 & 59.5 & & 0 \\
\hline 130 & 27 & 27 & 18.3 & 72.3 & & 0 \\
\hline 131 & 28 & 28 & 17.5 & 25.4 & & 0 \\
\hline 132 & 25 & 26 & 15.7 & 67.8 & & 0 \\
\hline 133 & 27 & 31 & 16.6 & 85.9 & & 0 \\
\hline 134 & 29 & 32 & 19.2 & 68.9 & & 0 \\
\hline 135 & 26 & 26 & 14.5 & 18.4 & & 0 \\
\hline 136 & 25 & 27 & 21.5 & 37.5 & & 0 \\
\hline 137 & 30 & 30 & 19.5 & 67.4 & & 0 \\
\hline 138 & 28 & 28 & 16.0 & 105.0 & & 0 \\
\hline 139 & 23 & 24 & 13.1 & 22.1 & & 0 \\
\hline 140 & 27 & 27 & 15.9 & 61.2 & & 0 \\
\hline & $\begin{array}{l}\text { AVG. STEM } \\
28.00\end{array}$ & $\begin{array}{l}\text { L. }(\mathrm{mm}) \\
29.05\end{array}$ & $\begin{array}{l}\text { TOTAL } \\
375.1\end{array}$ & $\begin{array}{l}\text { RY WEIGHTS } \\
1192.3\end{array}$ & $\begin{array}{l}(\mathrm{mg}) \\
1146.8\end{array}$ & TOTAL \\
\hline
\end{tabular}

\begin{tabular}{|c|c|c|c|c|c|c|}
\hline \multirow[b]{2}{*}{ TREE NO. } & \multicolumn{2}{|c|}{ STEM LENGTH (mon) } & DRY & WEIGHTS & (mg) & \multirow[b]{2}{*}{ NO. OF } \\
\hline & INITIAL & POST-EXP. & STEMS & NEEDLES & ROOTs & \\
\hline 281 & 26 & 37 & 23.3 & 101.3 & 144.7 & 0 \\
\hline 282 & 27 & 27 & 17.7 & 63.0 & 107.1 & 0 \\
\hline 283 & 31 & 35 & 29.3 & 119.5 & 210 : i & 0 \\
\hline 284 & 30 & 32 & 30.3 & 90.7 & 100 & 0 \\
\hline 285 & 29 & 30 & 23.5 & 109.2 & 230.2 & 0 \\
\hline 286 & 27 & 27 & 19.8 & 86.7 & 124.8 & 0 \\
\hline 287 & 27 & 27 & 24.5 & 89.3 & 134.8 & 0 \\
\hline 288 & 37 & 37 & 22.1 & 66.3 & 51.5 & 0 \\
\hline 289 & 29 & 31 & 22.3 & 81.1 & 136.2 & 0 \\
\hline 290 & 30 & 32 & 30.0 & 124.9 & 182.4 & 2 \\
\hline 291 & 29 & 32 & 27.9 & 100.5 & 139.6 & 0 \\
\hline 292 & 29 & 29 & 23.8 & 104.3 & 203.2 & 0 \\
\hline $\begin{array}{l}293 \\
294\end{array}$ & $\begin{array}{l}30 \\
28\end{array}$ & $\begin{array}{l}31 \\
28\end{array}$ & $\begin{array}{l}23.5 \\
25.8\end{array}$ & $\begin{array}{l}99.7 \\
84.7\end{array}$ & $\begin{array}{l}175.6 \\
105.0\end{array}$ & $\begin{array}{l}1 \\
0\end{array}$ \\
\hline 295 & 30 & 31 & 20.9 & 76.0 & 133.9 & 0 \\
\hline 296 & 33 & 39 & 39.5 & 138.4 & 188.0 & 0 \\
\hline 297 & 36 & 38 & 31.4 & 127.5 & 210.9 & 0 \\
\hline 298 & 28 & 36 & 33.0 & 139.9 & 122.8 & 1 \\
\hline 299 & 24 & 25 & 20.6 & 99.5 & 107.8 & 0 \\
\hline 300 & 29 & 37 & 25.2 & 112.9 & 165.9 & 0 \\
\hline
\end{tabular}

AVG. STEM L. (m) TOTAL DRY WEIGHTS (mg) $29.45 \quad 32.05 \quad 514.4 \quad 2015.4 \quad 2975.4$

TOTAL * BRANCHES

EXPERIMENTAL

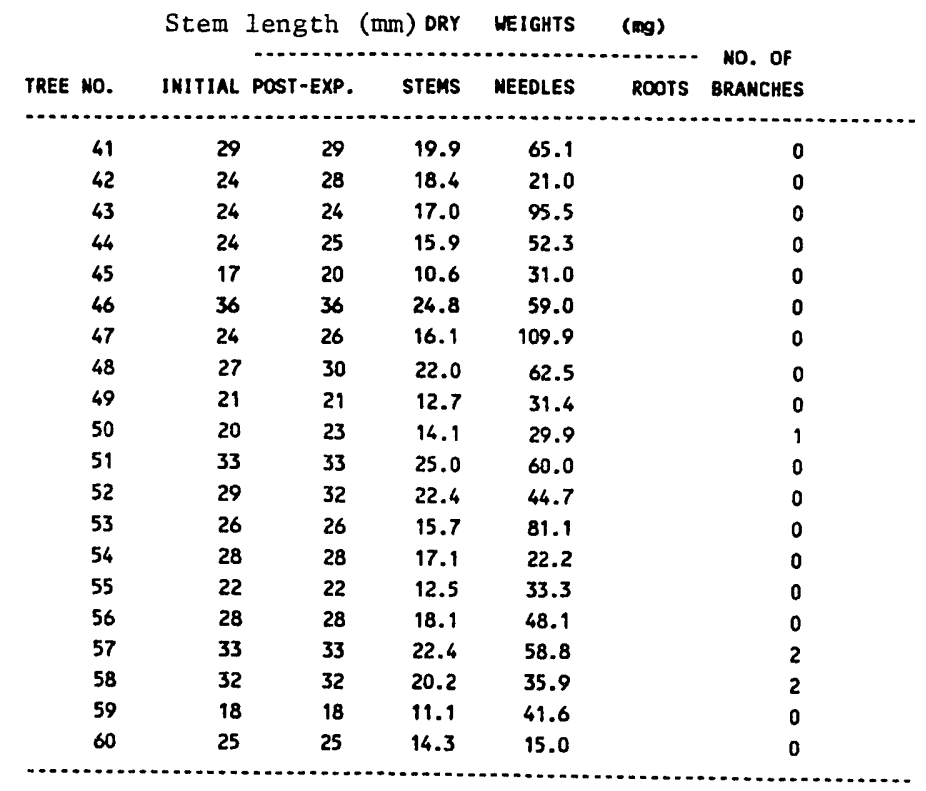

AVG. STEM L. ( $(\mathrm{mm})$

TOTAL DRY WEIGHTS (mg)

TOTAL * BRANCHES $\begin{array}{lllll}26.00 & 26.95 & 350.3 & 998.3 & 1080.6\end{array}$

\begin{tabular}{|c|c|c|c|c|c|c|c|}
\hline & STEM LENGTH & $4(\mathrm{~mm})$ & DRY & WEIGHTS & (mg) & & \\
\hline TREE NO. & INITIAL & POST-EXP. & stens & NEEDLES & RoOTs & $\begin{array}{l}\text { NO. OF } \\
\text { BRANCHES }\end{array}$ & \\
\hline 301 & 31 & 32 & 22.7 & 87.1 & 145.6 & 0 & \\
\hline 302 & 32 & 33 & 27.9 & 114.8 & 155.5 & 0 & \\
\hline 303 & 35 & 35 & 39.9 & 180.0 & 176.8 & 1 & \\
\hline 304 & 24 & 29 & 29.3 & 117.5 & 179.2 & 0 & \\
\hline 305 & 33 & 35 & 34.5 & 147.6 & 180.0 & 1 & \\
\hline 306 & 26 & 29 & 22.7 & 83.2 & 111.8 & 0 & \\
\hline 307 & 32 & 40 & 44.3 & 117.4 & 238.7 & 0 & \\
\hline 308 & 49 & 41 & 46.6 & 100.2 & 141.6 & 0 & \\
\hline 309 & 24 & 27 & 28.0 & 98.8 & 144.7 & 0 & \\
\hline 310 & 31 & 36 & 32.0 & 171.8 & 179.8 & 0 & \\
\hline 311 & 31 & 33 & 28.2 & 99.1 & 145.2 & 0 & \\
\hline 312 & 34 & 35 & 35.8 & 110.1 & 210.2 & 0 & . \\
\hline 313 & 23 & 26 & 27.1 & 93.8 & 112.5 & 0 & \\
\hline 316 & 27 & 30 & 25.0 & 101.0 & 169.3 & 0 & \\
\hline 315 & 32 & 36 & 38.0 & 158.0 & 233.9 & 0 & \\
\hline 316 & 22 & 28 & 19.2 & 48.8 & 66.0 & 0 & \\
\hline 317 & 30 & 32 & 34.8 & 150.6 & 241.5 & 0 & \\
\hline 318 & 24 & 29 & 26.3 & 143.2 & 164.4 & 2 & \\
\hline 319 & 23 & 28 & 21.0 & 121.3 & 150.2 & 0 & \\
\hline 320 & 39 & 47 & 43.4 & 133.8 & 157.8 & 0 & \\
\hline & $\begin{array}{r}\text { VG. STEN L } \\
29.7\end{array}$ & 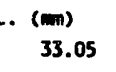 & $\begin{array}{l}\text { TOTAL } \\
626.7\end{array}$ & $\begin{array}{l}\text { RY WEIGHTS } \\
2377.9\end{array}$ & $\begin{array}{l}(\operatorname{mg}) \\
3304.7\end{array}$ & TOTAL & NCHES \\
\hline
\end{tabular}


TABLE A-6: Emergent Seedling Study, 2-Month Exposure Data

CONTROL

\begin{tabular}{|c|c|c|c|c|c|c|}
\hline \multirow[b]{2}{*}{ TREE NO. } & \multicolumn{2}{|c|}{ STEM LENGTH $(m)$} & DRY & WEIGHTS & $(m g)$ & \multirow{2}{*}{$\begin{array}{l}\text { NO. OF } \\
\text { BRANCHES }\end{array}$} \\
\hline & INITIALL & -EXP. & STEMS & MEEDLES & ROOIS & \\
\hline 141 & 25 & 28 & 21.9 & 123.1 & & 0 \\
\hline 142 & 31 & 36 & 15.7 & 130.5 & & 1 \\
\hline 143 & 33 & 36 & 21.1 & 151.0 & & 0 \\
\hline 144 & 29 & 32 & 18.3 & 67.1 & & 0 \\
\hline 145 & 34 & 39 & 22.1 & 50.8 & & 2 \\
\hline 146 & 29 & 32 & 22.7 & 106.6 & & 2 \\
\hline 147 & 28 & 31 & 22.8 & 85.5 & & 1 \\
\hline 148 & 22 & 23 & 16.4 & 136.8 & & 0 \\
\hline 149 & 28 & 28 & 35.4 & 84.0 & & 0 \\
\hline 150 & 28 & 28 & 22.9 & 123.4 & & 0 \\
\hline 151 & 31 & 33 & 26.4 & 79.7 & & 0 \\
\hline 152 & 40 & 42 & 12.8 & 112.8 & & 0 \\
\hline 153 & 32 & 35 & 13.2 & 122.2 & & 0 \\
\hline 154 & 20 & 22 & 22.1 & 55.8 & & 1 \\
\hline 155 & 37 & 38 & 24.8 & 72.2 & & 0 \\
\hline 156 & 36 & 39 & 21.8 & 137.5 & & 0 \\
\hline 157 & 23 & 28 & 28.1 & 120.5 & & 1 \\
\hline 158 & 40 & 45 & 40.3 & 127.9 & & 3 \\
\hline 159 & 24 & 28 & $2 c .4$ & 153.1 & & 3 \\
\hline 160 & 29 & 34 & 25.2 & 128.5 & & 1 \\
\hline & $\begin{array}{l}\text { AVG. STEM L } \\
29.95\end{array}$ & $\begin{array}{l}\text { m) } \\
2.85\end{array}$ & $\begin{array}{l}\text { TOTAL } \\
454.4\end{array}$ & $\begin{array}{l}\text { RY WEIGHTS } \\
2169.0\end{array}$ & $\begin{array}{l}(\mathrm{mg}) \\
1653.8\end{array}$ & $\begin{array}{c}\text { TOTAL \# BI } \\
15\end{array}$ \\
\hline
\end{tabular}

\begin{tabular}{|c|c|c|c|c|c|c|}
\hline \multirow{3}{*}{$\begin{array}{r}\text { TREE NO. } \\
261\end{array}$} & \multicolumn{2}{|c|}{$\begin{array}{l}\text { STEM LENGTH (m) } \\
\text { (m) }\end{array}$} & \multirow{2}{*}{$\begin{array}{c}\text { DRY } \\
\text { STEMS }\end{array}$} & \multirow{2}{*}{$\begin{array}{l}\text { WEIGHTS } \\
\text { MEEDLES }\end{array}$} & \multirow{2}{*}{$\begin{array}{l}\text { (mg) } \\
\text { Roots }\end{array}$} & \multirow{2}{*}{$\begin{array}{l}\text { MO. OF } \\
\text { BRANCHES }\end{array}$} \\
\hline & INITIAL & ExP. & & & & \\
\hline & 30 & 32 & 31.8 & 127.0 & 133.2 & 2 \\
\hline 262 & 30 & 32 & 35.7 & 107.1 & 180.5 & 0 \\
\hline 263 & 31 & 37 & 30.6 & 100.5 & 206.0 & 0 \\
\hline 264 & 34 & 38 & 49.0 & 188.5 & 299.8 & 1 \\
\hline 265 & 27 & 27 & 22.7 & 93.4 & 158.3 & 0 \\
\hline 266 & 40 & 43 & 35.3 & 115.2 & 221.1 & 0 \\
\hline 267 & 33 & 36 & 30.8 & 96.1 & 136.4 & 1 \\
\hline 268 & 31 & 34 & 28.2 & 100.0 & 147.9 & 1 \\
\hline 269 & 32 & 34 & 27.0 & 160.6 & 212.3 & 1 \\
\hline 270 & 33 & 33 & 28.7 & 138.6 & 213.7 & 1 \\
\hline 271 & 33 & 35 & 28.9 & 103.2 & 144.5 & 1 \\
\hline 272 & 30 & 30 & 30.5 & 119.4 & 172.9 & 1 \\
\hline 273 & 31 & 31 & $\therefore .1$ & 68.6 & 65.7 & 2 \\
\hline 274 & 33 & 33 & 22.1 & 119.9 & 106.9 & 4 \\
\hline 275 & 33 & 34 & 35.0 & 118.6 & 241.0 & 1 \\
\hline 276 & 36 & 41 & 43.5 & 145.5 & 251.7 & 1 \\
\hline $2 \pi$ & 28 & 30 & 21.6 & 94.0 & 160.7 & 1 \\
\hline 278 & 32 & 36 & 40.2 & 156.5 & 243.6 & 0 \\
\hline 279 & 26 & 29 & 25.2 & 112.9 & 189.2 & 1 \\
\hline 280 & 30 & 35 & 36.0 & 110.4 & 169.2 & 0 \\
\hline & $\begin{array}{l}\text { G. STEM L } \\
31.65\end{array}$ & 4.00 & $\begin{array}{l}\text { TOTAL } \\
624.9\end{array}$ & $\begin{array}{l}\text { RY MEIGHT } \\
2376.0\end{array}$ & $\begin{array}{l}(\mathrm{mg}) \\
3654.6\end{array}$ & $\begin{array}{r}\text { TOTAL * } \\
19\end{array}$ \\
\hline
\end{tabular}

EXPERIMENTAL

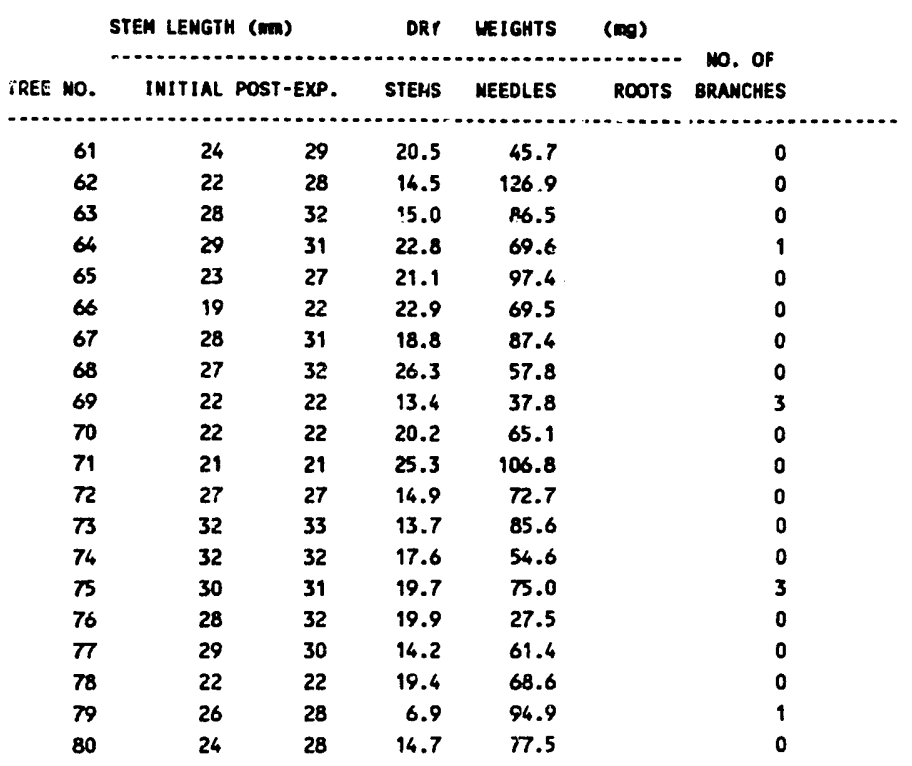

AVG. STEM L. (mon) $25.75 \quad 28.00$
TOTAL DRY WEIGHTS (mg)

TOTAL * BRANCHES 8 
TABLE A-7: Emergent Seedling Study, 3-Month Exposure Data

CONTROL

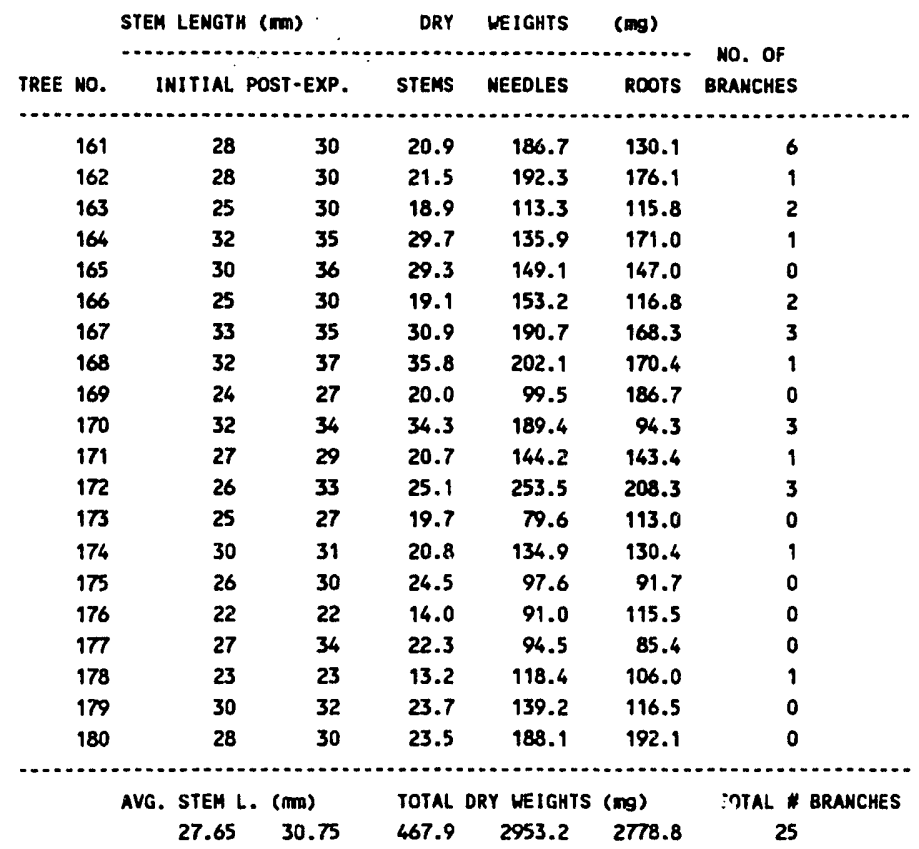

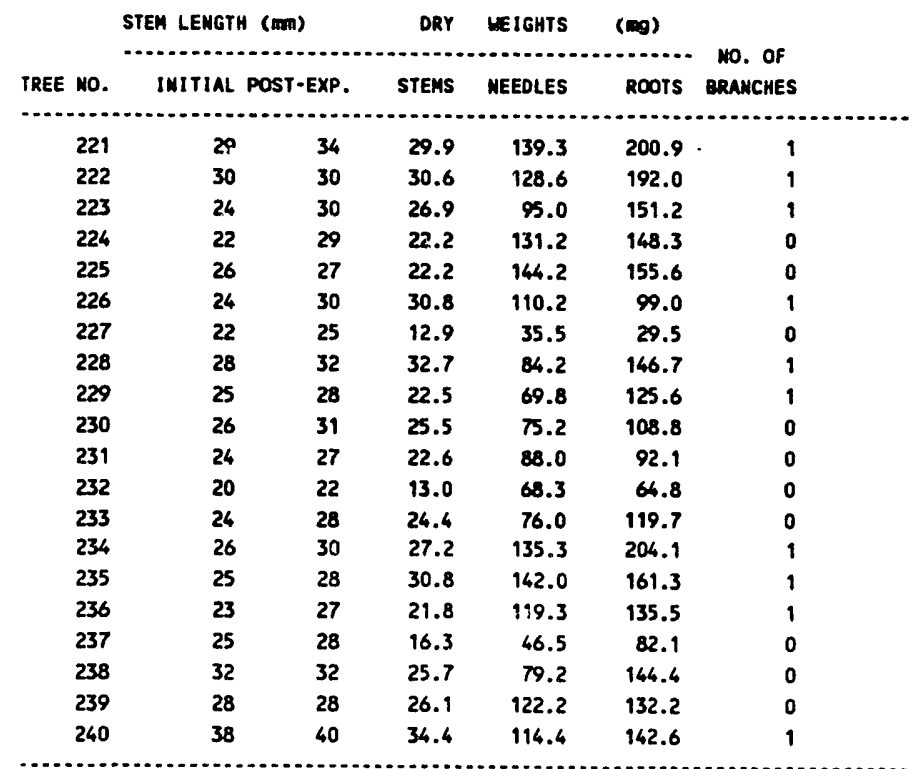

AVG. STEM L. (mim) TOTAL DRY WEIGHTS (mg)

TOTAL * BRANCHES $26.05 \quad 29.3$ $498.5 \quad 2004.4 \quad 2636.4$

EXPERIMENTAL

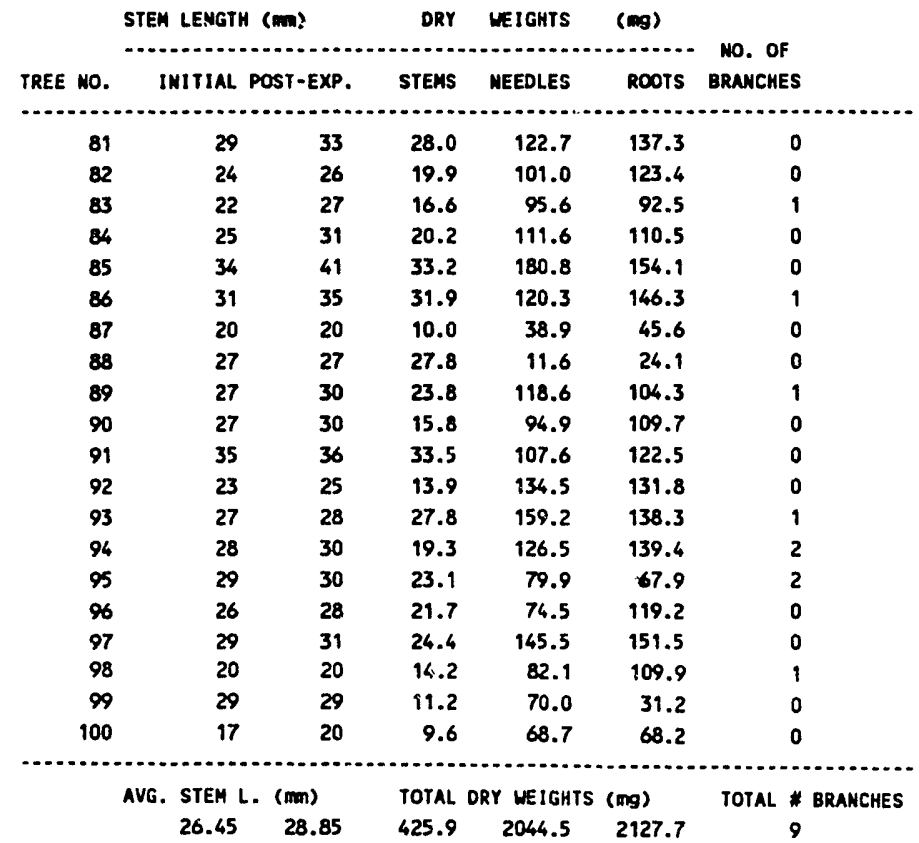

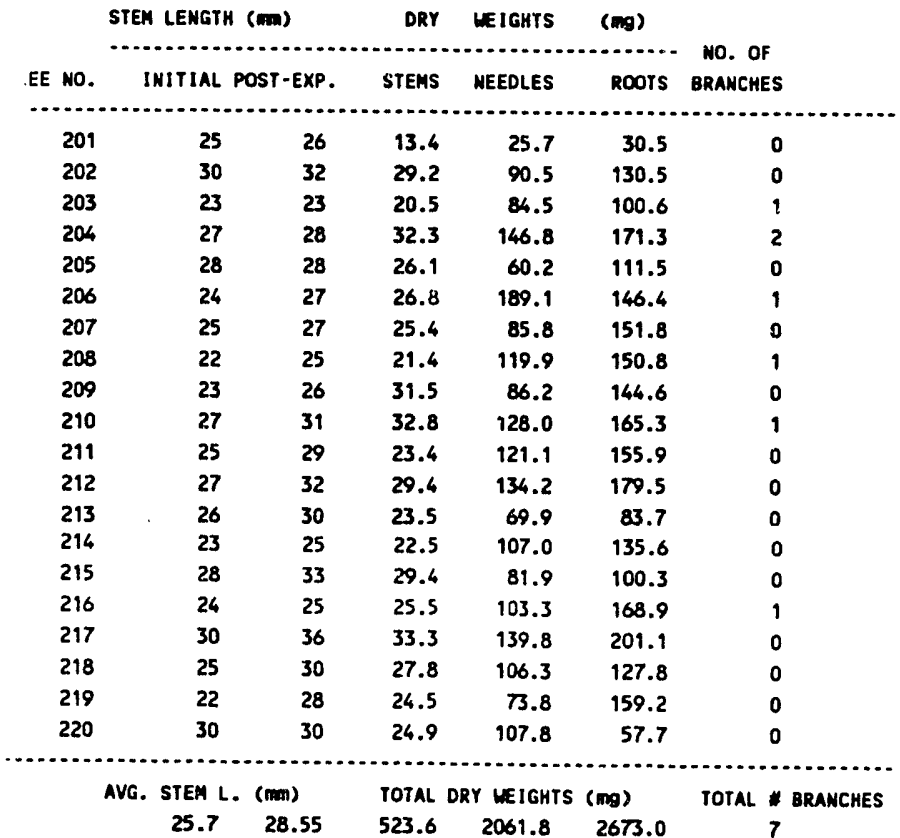




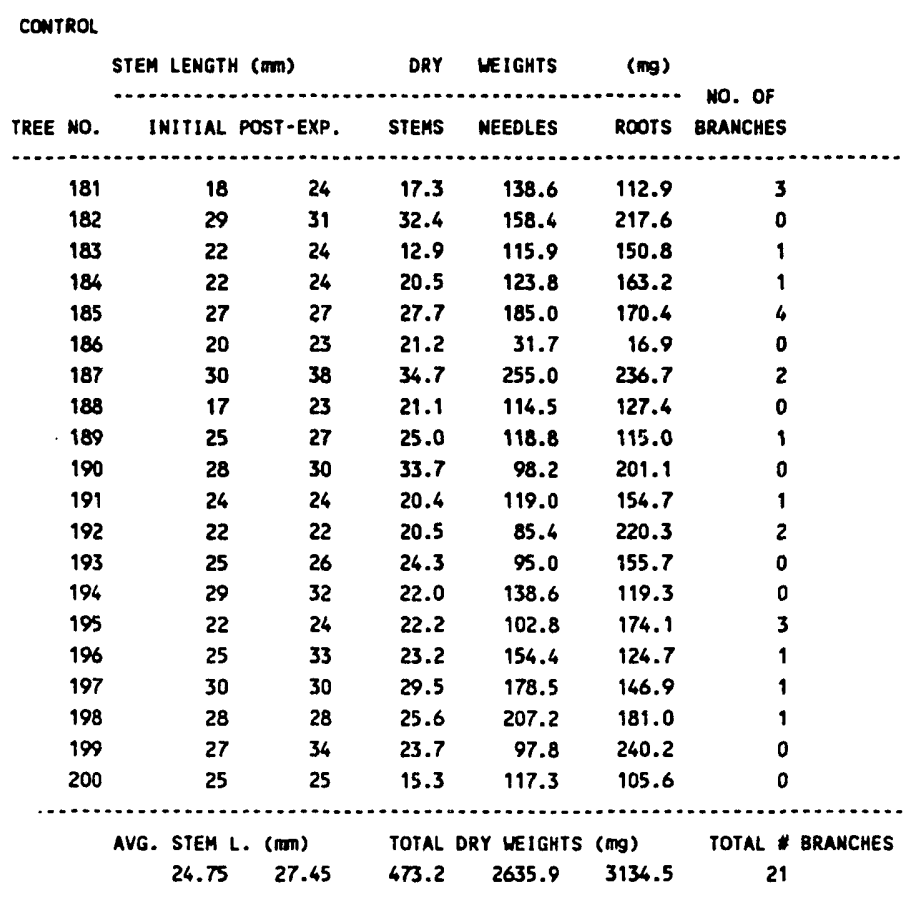

EXPERIMENTAL

STEM LEHGTH (mm)
TREE NO. DRY WEIGHTS (mg)
INITIAL POST-EXP. STEMS NEEDLES ROOTS BRAMCHES

\begin{tabular}{|c|c|c|c|c|c|c|}
\hline 101 & 25 & 33 & 27.5 & 233.7 & 256.5 & 1 \\
\hline 102 & 28 & 30 & 32.1 & 145.0 & 225.6 & 0 \\
\hline 103 & 24 & 29 & 25.7 & 146.5 & 210.0 & 1 \\
\hline 104 & 35 & 39 & 36.0 & 210.6 & 184.7 & 2 \\
\hline 105 & 21 & 23 & 0.0 & 84.8 & 36.5 & 0 \\
\hline 106 & 23 & 27 & 21.7 & 132.8 & 162.4 & 1 \\
\hline 107 & 39 & 44 & 51.7 & 170.1 & 269.9 & 2 \\
\hline 108 & 33 & 33 & 23.9 & 133.1 & 154.3 & 0 \\
\hline 109 & 24 & 27 & 30.0 & 199.0 & 190.5 & 2 \\
\hline 110 & 28 & 34 & 31.7 & 258.9 & 241.0 & 2 \\
\hline 111 & 30 & 35 & 26.8 & 126.3 & 142.9 & 1 \\
\hline 112 & 25 & 27 & 23.1 & 70.5 & 114.3 & 0 \\
\hline 113 & 30 & 35 & 28.9 & 134.6 & 206.1 & 0 \\
\hline 114 & 27 & 30 & 22.2 & 119.7 & 154.1 & 0 \\
\hline 115 & 27 & 29 & 27.5 & 127.1 & 151.8 & 0 \\
\hline 116 & 27 & 30 & 22.3 & 123.5 & 172.2 & 0 \\
\hline 117 & 24 & 27 & 19.3 & 7.5 & 109.1 & 0 \\
\hline 118 & 43 & 43 & 43.8 & 114.3 & 113.0 & 4 \\
\hline 119 & 28 & 34 & 38.0 & 106.4 & 148.9 & 0 \\
\hline 120 & 25 & 29 & 24.5 & 155.2 & 148.6 & 2 \\
\hline
\end{tabular}


TABLE A-9: Chronic Fumigation Study, Unexposed Controls, Pre-Fumigation Harvest

\begin{tabular}{|c|c|c|c|c|c|}
\hline TREE MO. & $\begin{array}{l}\text { STEM LENGTH (mD) } \\
\text { INITIAL }\end{array}$ & \begin{tabular}{c} 
DRY \\
\hdashline STEMS
\end{tabular} & $\begin{array}{l}\text { WEIGHTS } \\
\text { MEEDLES }\end{array}$ & $\begin{array}{l}\text { (mg) } \\
\text { ROOTS }\end{array}$ & $\begin{array}{l}\text { NO. OF } \\
\text { BRANCHES }\end{array}$ \\
\hline 581 & 100 & 203.3 & 466.1 & 414.5 & 4 \\
\hline 582 & 111 & 279.3 & 701.0 & 297.6 & 6 \\
\hline 583 & 112 & 180.9 & 433.2 & 212.1 & 1 \\
\hline 584 & 90 & 298.4 & 572.3 & 549.0 & 4 \\
\hline 585 & 70 & 117.0 & 396.5 & 705.3 & 0 \\
\hline 586 & 80 & 144.1 & 324.7 & 708.3 & 2 \\
\hline 587 & 90 & 259.5 & 983.4 & 432.0 & 5 \\
\hline 588 & 113 & 167.4 & 531.7 & 1013.5 & 2 \\
\hline 589 & 75 & 134.2 & 533.3 & 425.5 & 3 \\
\hline 590 & 95 & 196.6 & 566.0 & 349.1 & 2 \\
\hline 591 & 85 & 186.1 & 686.4 & 349.6 & 2 \\
\hline 592 & 80 & 159.0 & 549.9 & 195.6 & 0 \\
\hline 593 & 90 & 169.5 & 440.2 & 380.3 & 1 \\
\hline 594 & 100 & 177.1 & 568.7 & 445.6 & 3 \\
\hline 595 & 75 & 150.1 & 450.5 & 698.9 & 3 \\
\hline 596 & 83 & 212.3 & 520.0 & 557.1 & 1 \\
\hline 597 & 80 & 113.2 & 376.3 & 366.4 & 0 \\
\hline 598 & 65 & 160.4 & 464.0 & 467.2 & 2 \\
\hline 599 & 80 & 150.7 & 562.1 & 308.4 & 7 \\
\hline 600 & 102 & 141.1 & 468.8 & 573.3 & 3 \\
\hline
\end{tabular}

AVG. STEM L. (mm) TOTAL DRY WEIGHTS (grans) TOTAL \# BRANCHES $\begin{array}{llllll}88.8 & 0 & 3520.2 & 10595.1 & 9469.3 & 51\end{array}$

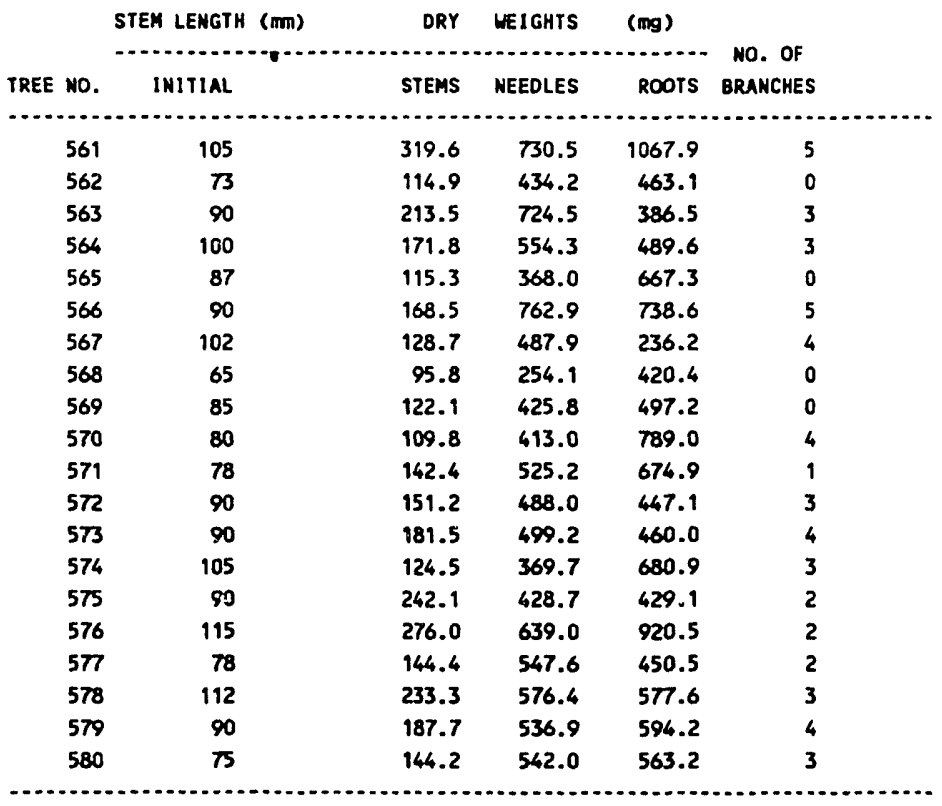

AVG. STEM L. (m) TOTAL DRY WEIGHTS (mg)
90
$0 \quad 11553.8 \quad 10307.9 \quad 11553.8$
51 
CONIROL

\begin{tabular}{|c|c|c|c|c|c|c|c|}
\hline \multirow{2}{*}{ TREE NO. } & \multicolumn{2}{|c|}{ STEM LENGTH (mm) } & DRY & WEIGHTS & (mg) & \multicolumn{2}{|c|}{ NO. OF BRAMCHES } \\
\hline & INITIAL & POST-EXP. & STEMS & NEEDLES & ROOTS & INITIAL & POST-EXP. \\
\hline & & & & 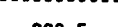 & $\cdots$ & & $\cdots$ \\
\hline 321 & 130 & 130 & 194.0 & 880.5 & 709.7 & 3 & 6 \\
\hline 322 & 100 & 106 & 166.9 & 709.6 & 512.8 & 3 & 6 \\
\hline 323 & 120 & 130 & 232.1 & 605.0 & 545.4 & 4 & 4 \\
\hline 324 & 115 & 120 & 175.9 & 491.6 & 478.9 & 0 & 4 \\
\hline 325 & 104 & 104 & 153.1 & 405.9 & 375.4 & 0 & 7 \\
\hline 326 & 105 & 110 & 180.5 & 625.9 & 664.7 & 3 & 3 \\
\hline 327 & 76 & 82 & 136.7 & 589.7 & 707.6 & 4 & 4 \\
\hline 328 & 100 & 105 & 195.2 & 859.0 & 716.7 & 3 & 6 \\
\hline 329 & 131 & 132 & 282.5 & 712.7 & 870.0 & 0 & 3 \\
\hline 330 & 103 & 112 & 229.2 & 856.2 & 703.2 & 3 & 6 \\
\hline 331 & 97 & 104 & 187.6 & 703.0 & 631.9 & 4 & 8 \\
\hline 332 & 102 & 105 & 241.5 & 673.2 & 735.3 & 0 & 5 \\
\hline 333 & 101 & 106 & 203.1 & 738.5 & 632.1 & 3 & 4 \\
\hline 334 & 102 & 110 & 201.7 & 778.8 & 610.4 & 1 & 6 \\
\hline 335 & 95 & 103 & 187.4 & 654.6 & 705.0 & 2 & 4 \\
\hline 336 & 90 & 104 & 178.7 & 735.3 & 579.6 & 3 & 4 \\
\hline 337 & 101 & 113 & 169.0 & 472.0 & 596.7 & 1 & 6 \\
\hline 338 & 122 & 124 & 186.1 & 631.6 & 730.7 & 1 & 5 \\
\hline 339 & 116 & 122 & 250.5 & 730.1 & 843.2 & 0 & 7 \\
\hline 340 & 100 & 110 & 221.4 & 687.1 & 652.0 & 2 & 5 \\
\hline & $\begin{array}{l}\text { AVG. STEM L } \\
105.5\end{array}$ & $\begin{array}{l}(\mathrm{mm}) \\
111.5\end{array}$ & $\begin{array}{l}\text { TOTAL } \\
3972.9\end{array}$ & $\begin{array}{l}\text { RY WEIGHTS } \\
13560.1\end{array}$ & $\begin{array}{l}\text { (mg) } \\
13001.3\end{array}$ & $\begin{array}{r}\text { TOTAL } \\
40\end{array}$ & $\begin{array}{r}\text { BRANCHES } \\
101\end{array}$ \\
\hline
\end{tabular}

\begin{tabular}{|c|c|c|c|c|c|c|c|c|}
\hline \multirow[b]{2}{*}{ TREE NO. } & \multicolumn{2}{|c|}{ STEM LENGTH (m) } & ORY & WEIGHTS & (mg) & \multicolumn{3}{|c|}{ MO. OF BRANCHES } \\
\hline & INITIALL & POST-EXP. & STEMS & NEEDLES & ROOTS & INITIAL & POST-EXP & \\
\hline 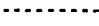 & $\cdots$ & $\ldots$ & . & . & $\ldots$ & $\cdots$ & $\ldots$ & $\ldots$ \\
\hline 601 & 120 & 130 & 391.2 & 690.9 & $\pi 52.3$ & 6 & 7 & 7 \\
\hline 602 & 120 & 132 & 299.3 & 793.0 & 686.1 & 6 & 13 & 13 \\
\hline 603 & 100 & 116 & 221.1 & 358.3 & 290.3 & 3 & 5 & 5 \\
\hline 604 & 115 & 128 & 407.3 & 1213.2 & 876.5 & 6 & 6 & 6 \\
\hline 605 & 120 & 123 & 336.4 & 794.7 & 832.3 & 5 & 8 & 8 \\
\hline 606 & 105 & 120 & 385.1 & 822.5 & 853.1 & 6 & 6 & 6 \\
\hline 607 & 110 & 105 & 228.4 & 761.5 & 808.9 & 6 & 7 & 7 \\
\hline 608 & 82 & 84 & 229.9 & 860.3 & 7619.0 & 5 & 5 & 5 \\
\hline 609 & 124 & 124 & 274.7 & 698.1 & 515.4 & 5 & 5 & 5 \\
\hline 610 & 110 & 118 & 293.8 & 999.6 & 815.7 & 6 & 10 & 10 \\
\hline 611 & 115 & 117 & 301.7 & 833.5 & 696.2 & 6 & 6 & 6 \\
\hline 612 & 130 & 140 & 405.1 & 789.9 & 895.1 & 2 & 5 & 5 \\
\hline 613 & 100 & 103 & 234.8 & 600.0 & 367.4 & 5 & 5 & 5 \\
\hline 614 & 100 & 118 & 339.1 & 865.5 & 681.1 & 7 & 7 & 7 \\
\hline 615 & 130 & 141 & 274.9 & 747.6 & 630.7 & 6 & 6 & 6 \\
\hline 616 & 120 & 130 & 361.8 & 854.4 & 653.5 & 4 & 9 & 9 \\
\hline 617 & 120 & 128 & 294.5 & 778.8 & 644.0 & 6 & 8 & 8 \\
\hline 618 & 97 & 105 & 217.4 & 501.1 & 378.4 & 5 & 7 & 7 \\
\hline 610 & 120 & 129 & 266.5 & 643.1 & 412.9 & 5 & 6 & 6 \\
\hline 620 & 112 & 120 & 343.9 & 827.6 & 912.3 & 5 & 5 & 5 \\
\hline
\end{tabular}

AVG. STEM L. (man) TOTAL DRY WEIGHTS (mos) TOTAL * BRAMCHES $\begin{array}{llllll}112.5 & 120.55 & 6106.9 & 15433.6 & 13403.2 & 105\end{array}$

EXPERIMENTAL

\begin{tabular}{|c|c|c|c|c|c|c|c|}
\hline \multirow{2}{*}{$\begin{array}{l}\text { TREE NO. } \\
.\end{array}$} & \multicolumn{2}{|c|}{ STEM LENGTH (naP) } & DRY & WEIGHTS & (mg) & \multicolumn{2}{|c|}{ NO. OF BRANCHES } \\
\hline & \multicolumn{2}{|c|}{ INITIAL POST-EXP. } & STEMS & MEEDLES & ROOTS & \multicolumn{2}{|c|}{ INITIAL POST-EXP. } \\
\hline & & & & (2) & & & 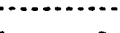 \\
\hline 401 & 100 & 100 & 299.5 & 932.9 & 838.9 & 5 & 5 \\
\hline 402 & 100 & 108 & 149.1 & 699.5 & 640.3 & 4 & 5 \\
\hline 403 & 103 & 105 & 138.6 & 580.3 & 387.2 & 2 & 2 \\
\hline 404 & 95 & 95 & 172.0 & 798.2 & 644.8 & 5 & 5 \\
\hline 405 & 102 & 105 & 187.6 & 796.6 & 610.0 & 4 & 6 \\
\hline 406 & 90 & 92 & 146.4 & 627.0 & 432.3 & 1 & 4 \\
\hline 407 & 92 & 100 & 163.7 & 704.7 & 538.9 & 2 & 4 \\
\hline 408 & 89 & 91 & 157.0 & 483.9 & 442.4 & 2 & 2 \\
\hline 409 & 120 & 123 & 191.0 & 519.1 & 566.8 & 1 & 4 \\
\hline 410 & 9 & 101 & 231.9 & 743.1 & 658.9 & 2 & 3 \\
\hline 411 & 70 & 80 & 123.8 & 514.9 & 523.1 & 2 & 3 \\
\hline 412 & 90 & 95 & 142.4 & 490.1 & 399.4 & 0 & 6 \\
\hline 413 & 9 & 100 & 177.5 & 908.4 & 640.7 & 4 & 4 \\
\hline 414 & 105 & 115 & 157.6 & 560.3 & 632.3 & 1 & 4 \\
\hline 415 & 101 & 111 & 199.1 & 558.5 & 402.2 & 4 & 5 \\
\hline 416 & 92 & 103 & 179.0 & 686.7 & 667.6 & 1 & 4 \\
\hline 417 & 106 & 111 & 284.0 & 663.6 & 640.4 & 3 & 3 \\
\hline 418 & 80 & 90 & 160.2 & 476.1 & 317.0 & 2 & 2 \\
\hline 419 & 100 & 100 & 187.3 & 630.8 & 294.1 & 3 & 3 \\
\hline 420 & 82 & 85 & 106.1 & 659.2 & 505.1 & 4 & 7 \\
\hline & AVG. STEM L & L. $(n m)$ & TOTAL & RY WEIGHT & (mg) & TOTAL * & * BRANCHES \\
\hline & 95.6 & 100.5 & 3553.8 & 13033.9 & 10762.4 & 52 & 81 \\
\hline
\end{tabular}

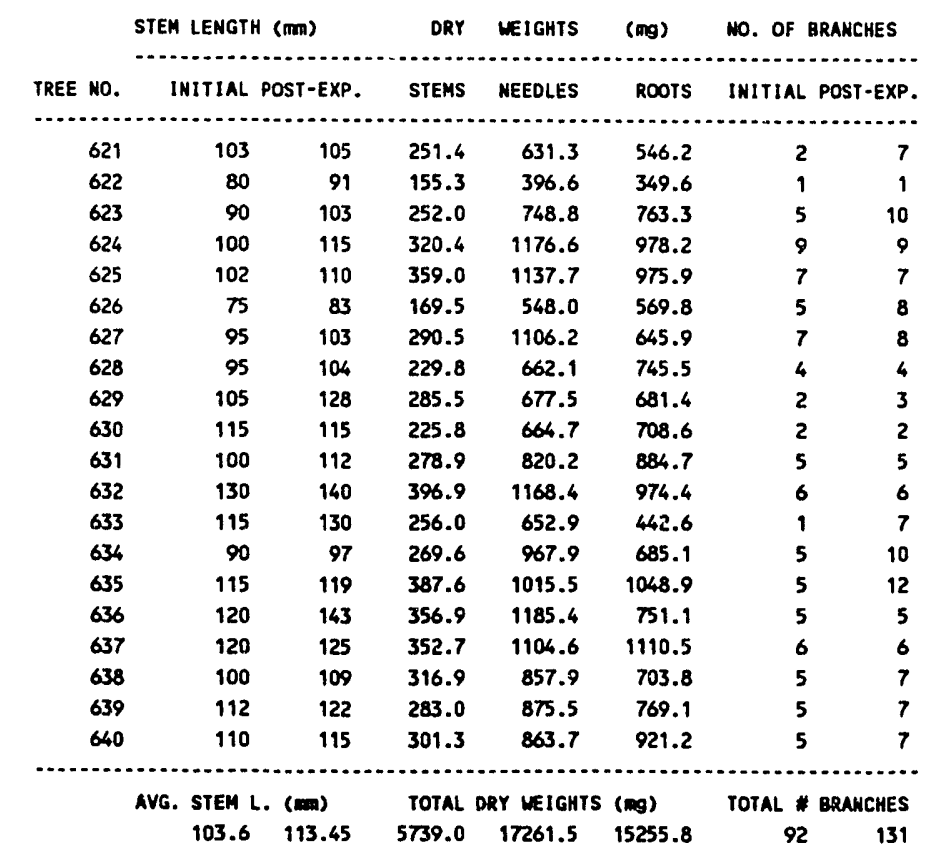


CONTROL

\begin{tabular}{|c|c|c|c|c|c|c|c|}
\hline \multirow[b]{2}{*}{ TREE NO. } & \multicolumn{2}{|c|}{ STEM LEMGTH (mm) } & DRY & WEIGHTS & (mg) & \multicolumn{2}{|c|}{ NO. OF BRANCHES } \\
\hline & INITIAL & $-\operatorname{Exp}$ & STEMS & MEEOLES & ROOTS & INITIAL & POST-EXP \\
\hline & & & & & & & \\
\hline 341 & 112 & 115 & 218.6 & 845.5 & 097.3 & 0 & 4 \\
\hline 342 & 110 & 113 & 213.4 & 560.3 & 606.6 & 9 & 3 \\
\hline 343 & 78 & 82 & 190.9 & 719.8 & 599.8 & 3 & 4 \\
\hline 344 & 98 & 108 & 234.7 & 735.0 & 617.7 & 3 & 6 \\
\hline 345 & 119 & 124 & 246.5 & 603.1 & 400.4 & 3 & 3 \\
\hline 346 & 110 & 110 & 198.9 & 531.4 & 670.5 & 0 & 3 \\
\hline 347 & 107 & 107 & 200.8 & 455.4 & 304.4 & 3 & 5 \\
\hline 348 & 86 & 90 & 153.4 & 499.8 & 350.7 & 4 & 10 \\
\hline 349 & 125 & 125 & 243.3 & 1001.4 & 847.4 & 5 & 6 \\
\hline 350 & 82 & 90 & 184.3 & 820.1 & 801.9 & 4 & 4 \\
\hline 351 & 118 & 121 & 256.4 & 1066.0 & 689.8 & 4 & 8 \\
\hline 352 & 98 & 98 & 163.7 & 613.2 & 554.6 & 1 & 1 \\
\hline 353 & 117 & 120 & 307.5 & 957.8 & 712.7 & 3 & 6 \\
\hline 354 & 83 & 90 & 153.8 & 688.8 & 813.1 & 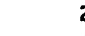 & 6 \\
\hline 355 & 95 & 95 & 135.1 & 784.7 & 586.3 & 2 & 7 \\
\hline 356 & 88 & 90 & 143.0 & $\pi 7.8$ & 803.2 & 2 & 6 \\
\hline 357 & 117 & 117 & 222.6 & 610.6 & 612.2 & 3 & 5 \\
\hline 358 & 87 & 93 & 143.7 & 890.3 & 458.7 & 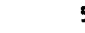 & 6 \\
\hline 359 & 117 & 117 & 249.0 & 524.7 & 492.8 & 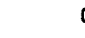 & 0 \\
\hline 360 & 110 & 114 & 167.9 & 724.4 & 642.7 & 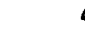 & 6 \\
\hline
\end{tabular}

AVG. STEM L. (mE) $102.85 \quad 105.95 \quad 4027.5 \quad 14410.1 \quad 12263$.
TOTAL BRAMCHES $52.0 \quad 99.0$

$\begin{array}{lll}\text { STEM LENGTH (mm) } & \text { DRY WEIGHTS (mg) NO. OF BRANCHES } \\ \text { TREE NO. INITIAL POST-EXP. STEMS NEEDLES ROOTS INITIAL POST-EXP. }\end{array}$

$\begin{array}{rrrrrrrr}521 & 90 & 96 & 344.2 & 1212.5 & 956.5 & 4 & 8 \\ 522 & 85 & 95 & 200.4 & 732.8 & 733.7 & 1 & 2 \\ 523 & 90 & 112 & 284.7 & 808.7 & 896.2 & 4 & 5 \\ 524 & 98 & 115 & 271.1 & 769.5 & 726.6 & 5 & 6 \\ 525 & 90 & 127 & 334.6 & 1033.6 & 734.9 & 2 & 6 \\ 526 & 85 & 108 & 212.6 & 708.0 & 574.3 & 1 & 4 \\ 527 & 115 & 128 & 185.5 & 403.2 & 376.0 & 0 & 4 \\ 528 & 95 & 116 & 295.7 & 580.6 & 629.5 & 2 & 5 \\ 529 & 80 & 75 & 139.6 & 440.6 & 347.0 & 0 & 1 \\ 530 & 100 & 117 & 213.7 & 710.3 & 734.4 & 1 & 4 \\ 531 & 90 & 113 & 303.3 & 785.2 & 1130.0 & 4 & 5 \\ 532 & 95 & 128 & 298.8 & 717.6 & 772.8 & 2 & 4 \\ 533 & 116 & 136 & 373.5 & 1084.9 & 694.0 & 5 & 17 \\ 534 & 102 & 125 & 283.6 & 777.9 & 539.2 & 2 & 9 \\ 535 & 76 & 106 & 286.4 & 854.6 & 892.9 & 0 & 12 \\ 536 & 75 & 95 & 263.7 & 940.0 & 855.9 & 4 & 13 \\ 537 & 110 & 124 & 313.2 & 753.8 & 731.8 & 2 & 5 \\ 538 & 108 & 115 & 354.1 & 973.8 & 1151.7 & 3 & 5 \\ 539 & 78 & 102 & 182.6 & 637.2 & 343.3 & 3 & 4 \\ 540 & 90 & 118 & 227.7 & 527.2 & 400.3 & 2 & 4 \\ \ldots \ldots \ldots \ldots & \ldots \ldots \ldots \ldots\end{array}$

AVG. STEM L. (

TOTAL DRY WEIGHTS (M) TOTAL \# BRAMCHES $\begin{array}{lllllll}93.4 & 112.55 & 5369.0 & 15452.0 & 14221.0 & 47 & 123\end{array}$

EXPERIMENTAL

\begin{tabular}{|c|c|c|c|c|c|c|c|}
\hline & \multicolumn{2}{|c|}{ STEM LENGTH (mm) } & DRY & WEIGHTS & (mg) & \multicolumn{2}{|c|}{ NO. OF BRANCHES } \\
\hline TREE NO. & INITIAL & -EXP. & STEMS & MEEDLES & ROOTS & INITIAL & POST-EXP. \\
\hline & & & & , & 724 & & \\
\hline 421 & 115 & 115 & 278.2 & 925.2 & 731.3 & 2 & 7 \\
\hline 422 & 91 & 95 & 158.5 & 730.6 & 405.1 & 4 & 4 \\
\hline 423 & 120 & 120 & 228.4 & 1090.9 & 640.9 & 1 & 5 \\
\hline 424 & 80 & 80 & 94.9 & 574.6 & 263.6 & 0 & 2 \\
\hline 425 & 105 & 107 & 217.6 & 569.4 & 544.3 & 4 & 5 \\
\hline 426 & 70 & 70 & 140.7 & 434.4 & 418.1 & 2 & 4 \\
\hline 427 & 95 & 95 & 176.7 & 680.7 & 459.0 & 3 & 6 \\
\hline 428 & 95 & 102 & 233.0 & 995.8 & 655.2 & 1 & 7 \\
\hline 429 & 71 & 85 & 84.8 & 555.5 & 332.6 & 1 & 4 \\
\hline 430 & 82 & 92 & 159.4 & 717.6 & 541.5 & 0 & 1 \\
\hline 431 & 80 & 85 & 230.1 & 1009.5 & 651.4 & 3 & 7 \\
\hline 432 & 70 & 70 & 88.6 & 751.1 & 444.3 & 2 & 6 \\
\hline 433 & 90 & 90 & 173.6 & 660.2 & 640.8 & 2 & 7 \\
\hline 434 & 122 & 126 & 37.5 & 672.8 & 455.6 & 2 & 5 \\
\hline 435 & $\pi$ & 80 & 116.0 & 708.4 & 494.1 & 1 & 3 \\
\hline 436 & 95 & 95 & 133.3 & 491.2 & 368.4 & 0 & 2 \\
\hline 437 & 106 & 120 & 232.7 & 848.9 & 513.8 & 1 & 5 \\
\hline 438 & 89 & 89 & 157.8 & 1179.2 & 610.5 & 2 & 6 \\
\hline 439 & 81 & 81 & 165.4 & 702.5 & 507.9 & 1 & 6 \\
\hline 440 & 88 & 92 & 147.7 & 491.5 & 520.8 & 3 & 4 \\
\hline & $\begin{array}{l}\text { 16. STEM } \\
91.1\end{array}$ & 94.45 & $\begin{array}{r}\text { TOTAL } \\
3254.9\end{array}$ & $\begin{array}{l}\text { RY WEIGHI } \\
14790.0\end{array}$ & $\begin{array}{l}(m g) \\
10199.2\end{array}$ & $\begin{array}{r}\text { TOTAL } \\
35\end{array}$ & $\begin{array}{r}\text { BRAKCHES } \\
96\end{array}$ \\
\hline
\end{tabular}

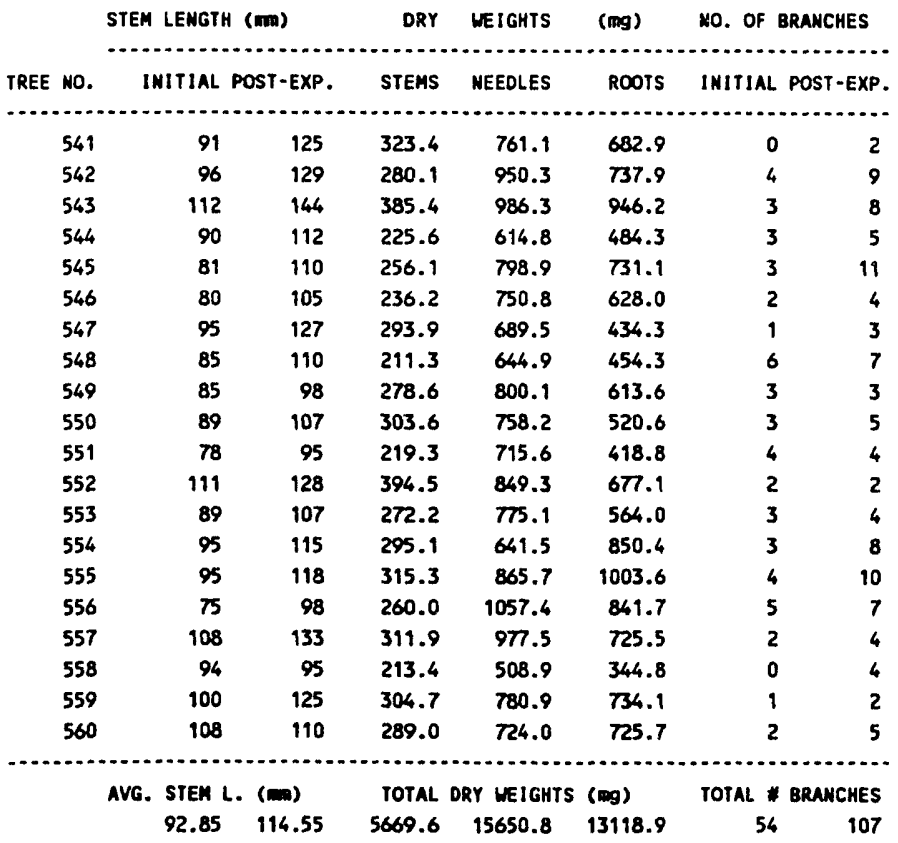


TABLE A-12: Chronic Fumigation Study, 3-month Exposure Data

CONTROL.

STEM LENGTH $(\mathrm{mm})$
TREE NO.
INITIAL POST-EXP. STEMS NEEOLES ROOTS INITIAL POST-EXP.

\begin{tabular}{|c|c|c|c|c|c|c|c|}
\hline \multirow[b]{2}{*}{ TREE NO. } & \multicolumn{2}{|c|}{ STEM LENGTH $(\mathrm{mm})$} & DRY & MEIGHTS & $(\mathrm{mg})$ & \multicolumn{2}{|c|}{ NO. OF BRANCHES } \\
\hline & INITIAL & POST-EXP. & STEMS & MEEDLES & ROOTS & INITIAL & POST-EXP \\
\hline & & & 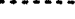 & & & & \\
\hline 501 & 87 & 97 & 217.6 & 819.9 & 765.6 & 1 & 5 \\
\hline 502 & 85 & 105 & 225.6 & 917.7 & 761.3 & 0 & 3 \\
\hline 503 & 96 & 100 & 126.5 & 606.3 & 583.3 & 3 & 4 \\
\hline 504 & 125 & 130 & 274.0 & 891.1 & 653.0 & 4 & 6 \\
\hline 505 & 100 & 108 & 197.9 & 606.1 & 459.2 & 1 & 6 \\
\hline 506 & 90 & 92 & 136.0 & 521.6 & 463.9 & 6 & 6 \\
\hline 507 & 120 & 125 & 252.8 & 689.7 & 819.3 & 1 & 2 \\
\hline 508 & 100 & 105 & 219.5 & 514.3 & 473.7 & 5 & 6 \\
\hline 509 & 120 & 120 & 208.2 & 687.2 & 654.4 & 5 & 7 \\
\hline 510 & 90 & 90 & 190.1 & 506.3 & 770.9 & 2 & 6 \\
\hline 511 & 105 & 105 & 212.9 & $5 \% .7$ & 818.9 & 0 & 3 \\
\hline 512 & 105 & 105 & 212.7 & 750.1 & 840.1 & 3 & 3 \\
\hline 513 & 145 & 150 & 274.9 & 824.5 & 578.4 & 1 & 3 \\
\hline 514 & 90 & 95 & 188.3 & 631.5 & 566.0 & 9 & 4 \\
\hline 515 & 118 & 125 & 230.4 & 746.2 & 848.5 & 2 & 5 \\
\hline 516 & 105 & 105 & 201.6 & 658.7 & 501.1 & 3 & 5 \\
\hline 517 & 72 & 72 & 116.2 & 443.8 & 436.6 & 3 & 3 \\
\hline 518 & 98 & 98 & 204.9 & 628.4 & 850.2 & 2 & 4 \\
\hline 519 & 78 & 80 & 154.0 & 824.3 & 764.5 & 4 & 6 \\
\hline 520 & 85 & 95 & 136.0 & 425.3 & 336.0 & 1 & 4 \\
\hline
\end{tabular}

AVG. STEM L. (m) TOTAL DRY WEIGHTS (mg) TOTAL \# BRAMCHES

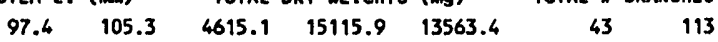

AVG. STEM L. (m) TOTAL DRY WEIGHTS (mg)

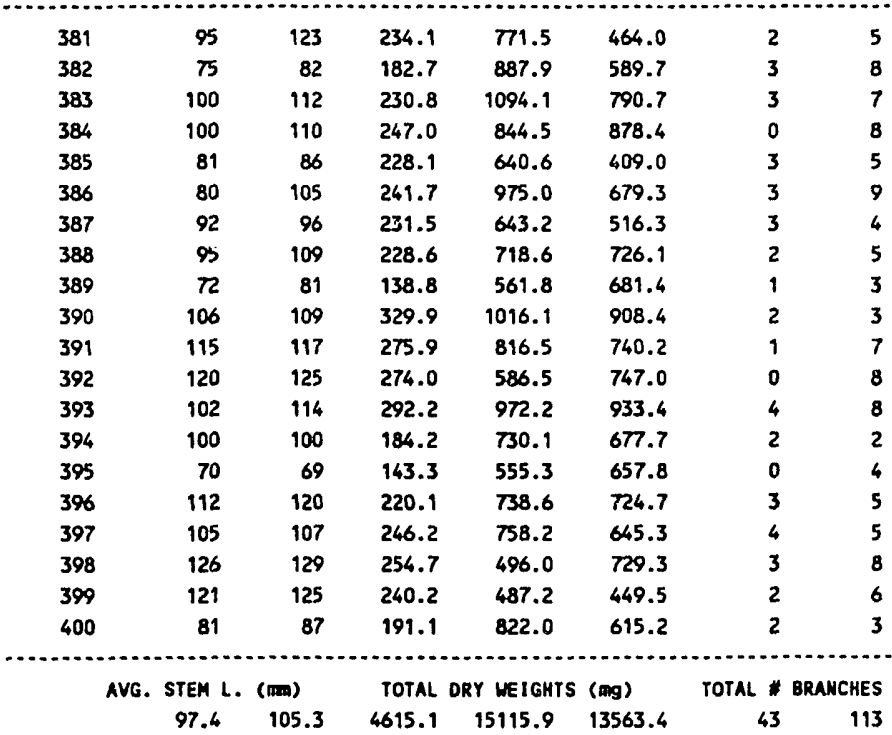

EXPERIMENTAL

\begin{tabular}{|c|c|c|c|c|c|c|c|}
\hline \multirow[b]{2}{*}{ TREE NO. } & \multicolumn{2}{|c|}{ STEM LENGTH $(\mathrm{mm})$} & DRY & WEIGHTS & (mg) & \multicolumn{2}{|c|}{ NO. OF BRANCHES } \\
\hline & INITIAL & T-EXP. & STEMS & NEEDLES & ROOTS & INITIAL & $\perp$ POST-EXP \\
\hline 441 & 75 & 80 & 209.1 & 741.6 & 765.9 & 4 & 6 \\
\hline 442 & 119 & 119 & 279.7 & 961.1 & 999.8 & & 2 \\
\hline 443 & 99 & 120 & 179.4 & 692.7 & 423.9 & & 3 \\
\hline 444 & 102 & 120 & 183.7 & 758.0 & 526.1 & & 2 \\
\hline 445 & 90 & 95 & 146.6 & 743.9 & 547.6 & & 3 \\
\hline 446 & 88 & 90 & 159.6 & 849.1 & 890.9 & & 3 \\
\hline 447 & 75 & 82 & 126.4 & 785.8 & 730.4 & & 2 \\
\hline 448 & 90 & 90 & 119.0 & 374.0 & 237.5 & & 2 \\
\hline 449 & 103 & 110 & 232.4 & 919.1 & 728.5 & & 2 \\
\hline 450 & 80 & 95 & 195.0 & 693.7 & 627.8 & & 3 \\
\hline 451 & 80 & 95 & 170.2 & 657.8 & 759.2 & & 1 \\
\hline 452 & 72 & 72 & 123.2 & 737.1 & 696.6 & & 2 \\
\hline 453 & 91 & 95 & 164.2 & 846.4 & 655.6 & & 2 \\
\hline 454 & 80 & 80 & 144.0 & 923.9 & 700.6 & & 4 \\
\hline 455 & 85 & 85 & 164.8 & 809.0 & 797.8 & & 1 \\
\hline 456 & 83 & 90 & 176.2 & 938.3 & 676.0 & & 2 \\
\hline 457 & 87 & 95 & 165.7 & 838.0 & 743.2 & & 1 \\
\hline 458 & $\pi$ & 90 & 103.2 & 571.2 & 471.3 & & 1 \\
\hline 459 & 87 & 92 & 179.5 & 824.5 & 651.3 & & 1 \\
\hline 460 & 90 & 95 & 173.0 & 664.8 & 676.7 & & 3 \\
\hline
\end{tabular}

AVG. STEM L. $(\mathrm{m})$ TOTAL DRY WEIGHTS (m) TOTAL * BRANCHES $\begin{array}{lllllll}87.65 & 94.5 & 3394.9 & 15330.0 & 13306.5 & 38 & 85\end{array}$

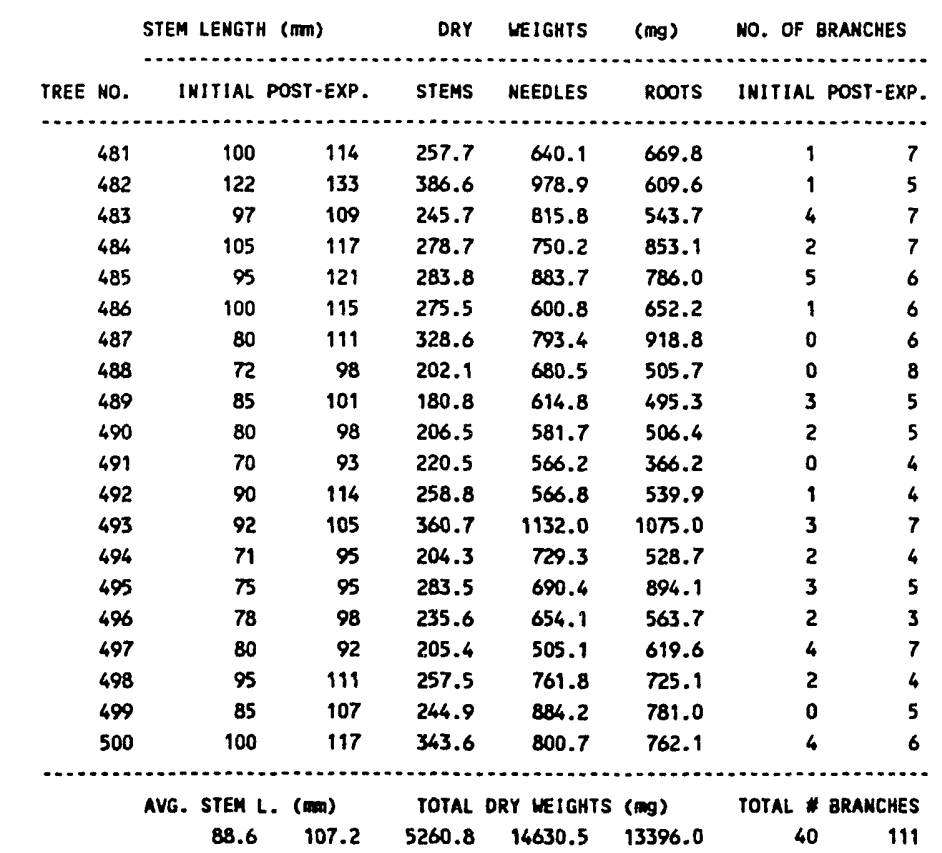




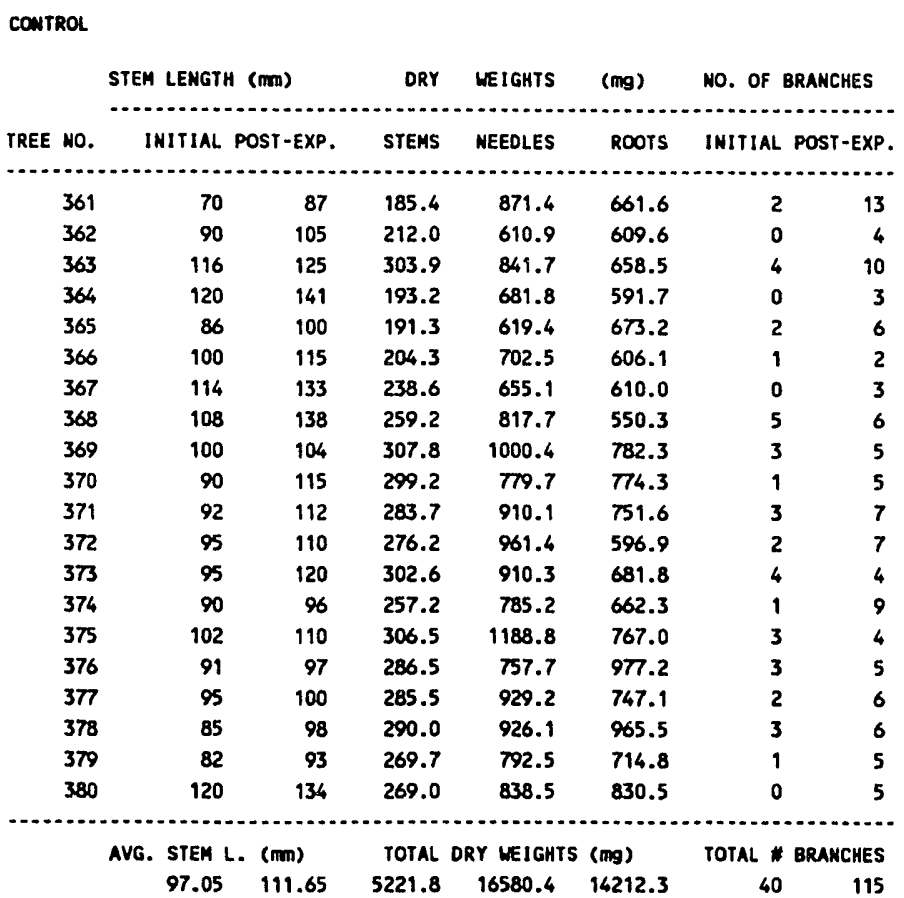

EXPERIMENTAL

\begin{tabular}{|c|c|c|c|c|c|c|c|c|}
\hline & STEM LENGTH & $H(\mathrm{~mm})$ & DRY & WEIGHTS & (mg) & \multicolumn{3}{|c|}{ NO. OF BRANCHES } \\
\hline TREE NO. & INITIAL & POST-EXP. & STEMS & MEEDLES & ROOTS & INITIAL & POST-EXP & KP. \\
\hline & & & & & & & & \\
\hline 461 & 85 & 119 & 349.9 & 1066.3 & 682.8 & 1 & & 8 \\
\hline 462 & 93 & 114 & 237.3 & 714.5 & 746.2 & 1 & & 2 \\
\hline 463 & 90 & 95 & 251.9 & 744.9 & 847.0 & 1 & & 4 \\
\hline 464 & 105 & 112 & 281.7 & 815.3 & 860.4 & 1 & & 6 \\
\hline 465 & 75 & 86 & 139.7 & 427.9 & 334.5 & 1 & & 5 \\
\hline 466 & 97 & 105 & 269.3 & 976.7 & 710.6 & 3 & & 7 \\
\hline 467 & 80 & 98 & 201.7 & 568.7 & 516.8 & 2 & & 4 \\
\hline 468 & 110 & 115 & 256.2 & 798.5 & 724.1 & 1 & & 7 \\
\hline 469 & 83 & 109 & 275.1 & 900.2 & 799.1 & 2 & 4 & 4 \\
\hline 470 & 97 & 117 & 313.4 & 802.2 & 714.4 & 1 & 3 & 3 \\
\hline 471 & 80 & 92 & 194.4 & 887.3 & 582.2 & 2 & 4 & 4 \\
\hline 472 & 93 & 100 & 175.5 & $m 7.2$ & 671.3 & 3 & 8 & 8 \\
\hline 473 & 83 & 100 & 196.5 & 849.2 & 500.4 & 3 & 7 & 7 \\
\hline 474 & 70 & 93 & 251.7 & 860.3 & 814.2 & 1 & 5 & 5 \\
\hline 475 & 93 & 105 & 339.3 & 1006.9 & 1001.0 & 0 & 6 & 6 \\
\hline 476 & 84 & 90 & 166.2 & 760.8 & 615.8 & 3 & 6 & 6 \\
\hline 477 & 94 & 105 & 263.1 & 623.8 & 756.7 & 4 & 5 & 5 \\
\hline 478 & 70 & 83 & 206.0 & 720.0 & 686.1 & 4 & 7 & 7 \\
\hline 479 & 93 & 117 & 272.5 & 999.1 & 738.6 & 4 & 6 & 6 \\
\hline 480 & 106 & 109 & 124.5 & 363.5 & 321.7 & 0 & 6 & 6 \\
\hline
\end{tabular}

AVG. STEN L. (mm) TOTAL DRY WEIGHTS (mg) $89.05 \quad 103.2 \quad 4765.9 \quad 15663.3 \quad 13623.9 \quad 38 \quad 110$ 
TABLE A-14: Chronic Fumigation Study, Sulfur Data

CONTROL

0.2 PPM SO2

RESULT UNCERTAINTY UNITS

1 MONTH EXPOSURE

$\begin{array}{rrr}1940.0000 & 100.0000 & \text { UG/G } \\ 1690.0000 & 80.0000 & \text { UG/G } \\ 2400.0000 & 120.0000 & \text { UG/G } \\ 1610.0000 & 80.0000 & \text { UG/G } \\ 1720.0000 & 80.0000 & \text { UG/G } \\ 1660.0000 & 80.0000 & \text { UG/G } \\ 2140.0000 & 100.0000 & \text { UG/G } \\ 1820.0000 & 90.0000 & \text { UG/G } \\ 1810.0000 & 90.0000 & \text { UG/G } \\ 2020.0000 & 100.0000 & \text { UG/G }\end{array}$

2 MONTH EXPOSURE

$1620.0000 \quad 80.0000 \quad$ UG/O

$1490.0000 \quad 80.0000 \quad$ UG/G

$1600.0000 \quad 80.0000 \quad$ UG/G

$1450.0000 \quad 80.0000$ UG/G

$1550.0000 \quad 80.0000$ UG/G

$1700.0000 \quad 80.0000 \quad$ UG/G

$1980.0000 \quad 100.0000 \quad$ UG/G

$1510.0000 \quad 80.0000 \quad$ UG/G

$1600.0000 \quad 70.0000$ UG/G

$1560.0000 \quad 70.0000$ UG/G

3 MONTH EXPOSURE

$1320.0000 \quad 60.0000 \quad U G / G$

$1250.0000 \quad 60.0000 \quad$ UG/G

$1370.0000 \quad 60.0000$ UG/G

$1290.0000 \quad 70.0000 \quad$ UG/G

$1190.0000 \quad 60.0000 \quad$ UG/G

$1420.0000 \quad 70.0000 \quad$ LU/G

$1940.0000 \quad 100.0000$ UG/G

$1920.0000 \quad 90.0000$ UG/G

$1650.0000 \quad 70.0000$ UG/G

$1910.0000 \quad 100.0000 \quad$ UG/G

4 MONTH EXPOSURE

$\begin{array}{rrr}1910.0000 & 100.0000 & \text { UG/G } \\ 1780.0000 & 90.0000 & \text { UG/G } \\ 1600.0000 & 80.0000 & \text { UG/G } \\ 2000.0000 & 100.0000 & \text { UG/G } \\ 1420.0000 & 70.0000 & \text { UG/G } \\ 1660.0000 & 80.0000 & \text { UG/G } \\ 1500.0000 & 70.0000 & \text { UG/G } \\ 1310.0000 & 70.0000 & \text { UG/G } \\ 1680.0000 & 80.0000 & \text { UG/G } \\ 2300.0000 & 120.0000 & \text { UG/G }\end{array}$

RESULT UNCERTAINTY UNITS

1 MONTH EXPOSURE

$2010.0000 \quad 100.0000 \quad$ UG/G

$2150.0000 \quad 100.0000 \quad U G / G$

$2010.0000 \quad 100.0000$ UG/G

$2610.0000 \quad 130.0000 \quad$ UG/G

$1810.0000 \quad 90.0000 \quad$ UG/G

$2410.0000 \quad 120.0000$ UG/G

$2410.0000 \quad 120.0000$ UG/G

$2560.0000 \quad 130.0000 \quad$ UG/G

$1930.0000 \quad 100.0000$ UG/G

$2360.0000 \quad 120.0000$ UG/G

\begin{tabular}{lrr}
\multicolumn{3}{c}{2 MONTH EXPOSURE } \\
2130.0000 & 100.0000 & UG/G \\
2200.0000 & 110.0000 & UG/G \\
2260.0000 & 120.0000 & UG/G \\
1500.0000 & 80.0000 & UG/G \\
2520.0000 & 130.0000 & UG/G \\
2270.0000 & 120.0000 & UG $/ G$ \\
1900.0000 & 100.0000 & UG/G \\
2180.0000 & 110.0000 & UG/G \\
2390.0000 & 150.0000 & UG/G \\
1810.0000 & 90.0000 & UG/G
\end{tabular}

3 MONTH EXPOSURE

$2060.0000 \quad 100.0000$ UG/G

$2320.0000 \quad 120.0000 \quad$ UG/G

$3020.0000 \quad 150.0000 \quad$ UG/G

$2660.0000 \quad 130.0000 \quad$ UG/G

$2710.0000 \quad 130.0000 \quad$ UG/G

$2750.0000 \quad 130.0000 \quad$ UG/G

$2980.0000 \quad 150.0000 \quad$ UG/G

$3190.0000 \quad 160.0000 \quad$ UG/G

$2690.0000 \quad 130.0000$ UG/G

$2770.0000 \quad 140.0000$ UG/G

\section{MONTH EXPOSURE}

$2690.0000 \quad 130.0000 \quad$ UG/G

$2740.0000 \quad 130.0000 \quad$ UG/G

$2640.0000 \quad 130.0000$ UG/G

$2830.0000 \quad 140.0000 \quad$ UG/G

$2900.0000 \quad 140.0000 \quad$ UG/G

$2350.0000 \quad 120.0000 \quad$ UG/G

$2690.0000 \quad 130.0000$ UG/G

$3210.0000 \quad 160.0000$ UG/G

$2770.0000 \quad 140.0000 \quad$ UG/G

$3000.0000 \quad 150.0000 \quad$ UG/G 
